\title{
Exposure of tropoelastin to peroxynitrous acid gives high yields of nitrated tyrosine residues, di-tyrosine cross-links and altered protein structure and function
}

Degendorfer, Georg; Chuang, Christine Yu-Nung; Mariotti, Michele; Hammer, Astrid; Hoefler, Gerald; Hägglund, Per; Malle, Ernst; Wise, Steven G.; Davies, Michael J.

\section{Published in:}

Free Radical Biology \& Medicine

Link to article, DOI:

10.1016/j.freeradbiomed.2017.11.019

Publication date:

2018

Document Version

Peer reviewed version

Link back to DTU Orbit

Citation (APA):

Degendorfer, G., Chuang, C. Y-N., Mariotti, M., Hammer, A., Hoefler, G., Hägglund, P., Malle, E., Wise, S. G., \& Davies, M. J. (2018). Exposure of tropoelastin to peroxynitrous acid gives high yields of nitrated tyrosine residues, di-tyrosine cross-links and altered protein structure and function. Free Radical Biology \& Medicine, 115, 219-231. https://doi.org/10.1016/j.freeradbiomed.2017.11.019

\section{General rights}

Copyright and moral rights for the publications made accessible in the public portal are retained by the authors and/or other copyright owners and it is a condition of accessing publications that users recognise and abide by the legal requirements associated with these rights.

- Users may download and print one copy of any publication from the public portal for the purpose of private study or research.

- You may not further distribute the material or use it for any profit-making activity or commercial gain

- You may freely distribute the URL identifying the publication in the public portal 


\section{ACCEPTED MANUSCRIPT}

Exposure of tropoelastin to peroxynitrous acid gives high yields of nitrated

tyrosine residues, di-tyrosine cross-links and altered protein structure and function

Georg Degendorfer ${ }^{1}$, Christine Y. Chuang ${ }^{2}$, Michele Mariotti ${ }^{3}$, Astrid Hammer ${ }^{4}$, Gerald

Hoefler $^{5}$, Per Hägglund ${ }^{2,3}$, Ernst Malle ${ }^{6}$ Steven Wise ${ }^{1,7}$, Michael J. Davies ${ }^{1,2,7}$

${ }^{1}$ The Heart Research Institute, Sydney, Australia;

${ }^{2}$ Dept. of Biomedical Sciences, Panum Institute, University of Copenhagen, Copenhagen,

Denmark;

${ }^{3}$ Department of Biotechnology and Biomedicine, Technical University of Denmark, Kongens Lyngby, Denmark;

${ }^{4}$ Institute of Cell Biology, Histology and Embryology, Medical University of Graz, Graz, Austria;

${ }^{5}$ Institute of Pathology, Medical University of Graz, Graz, Austria;

${ }^{6}$ Institute of Molecular Biology and Biochemistry, Medical University of Graz, Graz, Austria;

${ }^{7}$ Faculty of Medicine, University of Sydney, Sydney, Australia

*Corresponding author. E-mail address: davies@sund.ku.dk (M.J. Davies) 


\section{ACCEPTED MANUSCRIPT}

\section{ABSTRACT}

Elastin is an abundant extracellular matrix protein in elastic tissues, including the lungs, skin and arteries, and comprises $30-57 \%$ of the aorta by dry mass. The monomeric precursor, tropoelastin (TE), undergoes complex processing during elastogenesis to form mature elastic fibers. Peroxynitrous acid $(\mathrm{ONOOH})$, a potent oxidizing and nitrating agent, is formed in vivo from superoxide and nitric oxide radicals. Considerable evidence supports $\mathrm{ONOOH}$ formation in the inflamed artery wall, and a role for this species in the development of human atherosclerotic lesions, with $\mathrm{ONOOH}$-damaged extracellular matrix implicated in lesion rupture. We demonstrate that TE is highly sensitive to $\mathrm{ONOOH}$, with this resulting in extensive dimerization, fragmentation and nitration of Tyr residues to give 3-nitrotyrosine (3nitroTyr). This occurs with equimolar or greater levels of oxidant and increases in a dosedependent manner. Quantification of Tyr loss and 3-nitroTyr formation indicates extensive Tyr modification with up to two modified Tyr per protein molecule, and upto $8 \%$ conversion of initial $\mathrm{ONOOH}$ to 3-nitroTyr. These effects were modulated by bicarbonate, an alternative target for ONOOH. Inter- and intra-protein di-tyrosine cross-links have been characterized by mass spectroscopy. Examination of human atherosclerotic lesions shows colocalization of 3nitroTyr with elastin epitopes, consistent with TE or elastin modification in vivo, and also an association of 3-nitroTyr containing proteins and elastin with lipid deposits. These data suggest that exposure of TE to ONOOH gives marked chemical and structural changes to TE and altered matrix assembly, and that such damage accumulates in human arterial tissue during the development of atherosclerosis.

Graphical abstract 


\section{ACCEPTED MANUSCRIPT}
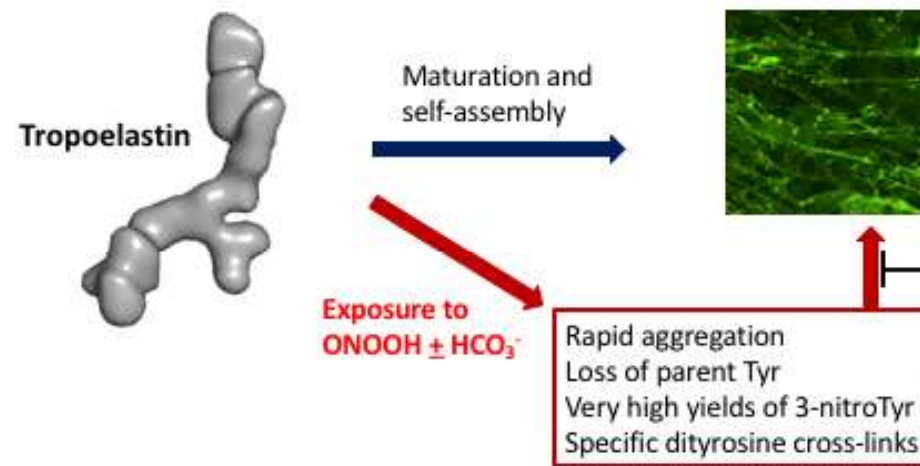

Mature elastin fibres

Major elastic protein in extracellular matrix of skin and major arteries

Impaired fibre assembly?

Co-localization of elastin with 3-nitroTyr and macrophages in human atherosclerotic lesions

Abbreviations

ABTS, 2,2'-azino-bis(3-ethylbenzothiazoline-6-sulphonic acid); BSA, bovine serum albumin;

DOPA, 3,4-dihydroxyphenylalanine; ECM, extracellular matrix; mAb, monoclonal antibody; 3-nitroTyr, 3-nitrotyrosine; ONOOH, the physiological mixture of peroxynitrous acid and its anion; pAb, polyclonal antibody; PBST, phosphate-buffered saline with Tween 20; TE, tropoelastin.

Keywords: Extracellular matrix; peroxynitrous acid; peroxynitrite; tropoelastin; elastin; protein oxidation; 3-nitrotyrosine; nitration; cross-links; di-tyrosine 


\section{ACCEPTED MANUSCRIPT}

\section{INTRODUCTION}

Elastic fibres are large extracellular matrix (ECM) macromolecules composed of microfibrils and elastin. These structures are highly abundant and responsible for the resilience and recoil capabilities of tissue and organs [1], with elastin constituting $30-57 \%$ of the aorta and $28-32 \%$ of major vascular vessels by dry mass [2-4]. Elastin is predominantly expressed during embryogenesis and tissue development and has a low turnover rate in healthy tissues. However, if elastic fibers are subject to injury, tissue repair mechanisms are initiated and synthesis of new elastin can be rapidly activated [5].

Impaired elastogenesis contributes to a number of human pathologies (e.g. supravalvular aortic stenosis [6], cutis laxa [7], Hurler disease [8], and Costello syndrome [9]). Disruption of the elastin gene, by targeted inactivation, indicates that elastin plays an essential role in arterial morphogenesis $[10,11]$. Homozygous elastin-deficient mice die of obstructive arterial disease after birth [10], whereas heterozygote mice with one allele for elastin show increased elastic lamellae in their arteries [11]. It is known that arterial development is associated with an increase in the number of elastic lamellae [11]. These changes are perturbed during the development of atherosclerotic plaques [12], as a result of flow-induced dilatation [13], and non-atherosclerotic intimal thickening [14,15]. A number of stimuli linked with atherosclerosis can evoke elastogenesis [16,17], with duplication of elastic lamellae detected in healed arteritis and some atheroma. The structure and integrity of elastin within the artery wall is known to change with age $[18,19]$ and it has been reported that elastin fragments can stimulate the development of atherosclerosis through modulation of immune signalling pathways (Neu1-PI3K-gamma) [20].

The precursor protein of mature elastin, tropoelastin (TE), is encoded by a single gene, with 11 different isoforms reported to date [21]. Elastogenic cells such as smooth 


\section{ACCEPTED MANUSCRIPT}

muscle cells, fibroblasts and macrophages, express and release monomeric TE in the extracellular space where it forms clusters bound to integrins and glycosaminoglycans on the cell surface $[22,23]$. Elastogenesis, the secretion, coacervation and deposition of TE onto elastic fibres, and crosslinking of elastin monomers is a multistep process involving interaction with other matrix proteins including fibrillin-1, fibulins-4 and -5 and perlecan [2426]. Coacervation, the self-assembly of monomeric tropelastin to spherical globules, is an entropically-driven reversible process [4]. Increasing temperature supresses clathrate-like associated water from hydrophobic domains and allows these domains to align and aggregate $[21,27]$. TE-spherols are deposited onto a scaffold of microfibrils and are cross-linked $[28,29]$. Lysine residues are oxidised by the enzyme lysyl oxidase to form allysine, with spontaneous condensation of two allysine molecules, or an allysine, with an another Lys residues giving rise to irreversible crosslinks and elastic fibre growth $[21,30]$.

It has been shown that there are significant changes in elastin content within the artery wall during the development of cardiovascular disease and particularly atherosclerosis [31,32]. Elastic fibre content within the plaque area has been reported to increase with this associated with increased lipid deposition and binding of calcium ions, with up to $40 \%$ of the total calcium content of lesions reported to be bound to elastin [33]. In contrast, elastin levels within the fibrous cap of lesions appears to decrease during lesion development, and this is believed to play a role in the weakening of this structure making it more prone to rupture [34], a major cause of heart attacks and strokes $[35,36]$.

Macrophages are known to accumulate at sites of inflammation, including within the artery wall, with these cells reported to play a key role in ECM remodelling via altered excretion and activation of matrix metalloproteinases (MMPs) and their inhibitors (tissue inhibitors of metalloproteinases, TIMPs) [37], with the finely-tuned balance between these activities appearing to be altered during the development and progression of atherosclerosis 


\section{ACCEPTED MANUSCRIPT}

$[38,39]$. Activated macrophages are also known to release a battery of reactive oxidants via the activities of NADPH oxidases (which generate superoxide radicals, $\mathrm{O}_{2}^{-}$, and hydrogen peroxide, $\mathrm{H}_{2} \mathrm{O}_{2}$ ) and inducible nitric oxide synthase, which generate nitric oxide, NO [40]. The rapid (diffusion-controlled) reaction of $\mathrm{O}_{2}{ }^{-\cdot}$ with $\mathrm{NO}$ yields the powerful oxidant peroxynitrous acid $(\mathrm{ONOOH})$, which exists at physiological $\mathrm{pH}$ values in equilibrium with its less-reactive anion form, peroxynitrite $\left(\mathrm{ONOO}^{-}, \mathrm{pKa} 6.7\right)$ [41,42]. ONOOH can undergo both direct (2-electron) oxidation reactions, as well as undergo limited homolysis to give hydroxyl radical $(\mathrm{HO} \cdot)$ and nitrogen dioxide $\left(\mathrm{NO}_{2}{ }^{\circ}\right)$ radicals $[43,44]$. In the presence of physiological concentrations of $\mathrm{CO}_{2}$ (which is in equilibrium with $\sim 25 \mathrm{mM} \mathrm{HCO}_{3}{ }^{-}$), the adduct species peroxynitrosocarbonate, $\mathrm{ONOOCO}_{2}^{-}$, is formed that can also induce direct oxidations and give rise to the radicals $\mathrm{CO}_{3}{ }^{-\cdot}$ and $\mathrm{NO}_{2}{ }^{\cdot}$ as a result of homolysis [43]. Both ONOOH and $\mathrm{ONOOCO}_{2}^{-}$can give rise to nitrated products from biological targets, with these including 3nitrotyrosine (3-nitroTyr), a product of protein-bound tyrosine, and 6-nitrotryptophan, a product of protein-bound tryptophan $[43,45]$. These stable products are believed to arise via the initial formation of Tyr-derived phenoxyl radicals, and Trp-derived indolyl radicals, and subsequent reaction with $\mathrm{NO}_{2} \cdot$ to give nitrated products. 3-NitroTyr has been reported to be present at elevated levels in all grades of human atherosclerotic lesions and present on multiple proteins [46], including high- and low-density-lipoproteins [47], and the ECM materials perlecan [48], laminin [49] and fibronectin [50]. Furthermore, immunoglobulins against 3-nitroTyr epitopes have been detected in human atherosclerotic lesions and the circulation of subjects with coronary artery disease, linking oxidant production and activation of the immune system [51]. The role of oxidants in modifying ECM and its consequences has been reviewed [52-54]. ECM modification by ONOOH can result in changes in cell function, including altered cell adhesion and proliferation and changes in gene regulation and cytokine expression [54]. Elastin isolated from plaques has been reported to have an altered amino acid 


\section{ACCEPTED MANUSCRIPT}

composition and this is thought to be a prerequisite for the binding of cholesterol esters (from low-density lipoproteins) within plaques, a process that does not appear to occur to a significant extent with normal elastin [34,55]. Vascular remodeling, a major feature of atherosclerotic plaque development, has also been reported to be characterized by elastin fragmentation, a decrease in overall elastin content, and an increase in both collagen content and collagen crosslinking. These processes have been associated with increased arterial stiffness and calcification [19,31,56-58].

As elastin is present in many tissues in close proximity to other ECM proteins that are oxidised by $\mathrm{ONOOH}$ (e.g. perlecan $[26,48]$ ), we hypothesized that elastin would also be a likely target, and due to its high abundance in major vessels might consume a major portion of $\mathrm{ONOOH}$ or $\mathrm{ONOOCO}_{2}^{-}$generated in vivo. Previous studies using very high levels of ONOOH support this assertion $[59,60]$. Furthermore due to its unusual amino acid composition (TE contains no Met, Trp, His or free Cys residues, which are all favoured targets of ONOOH $[61,62])$, and a relatively high content of Tyr residues (15), it might be expected that this protein would give rise to particularly high yields of 3-nitroTyr. Such modifications might affect both the structure and biological activity of this protein. As previous studies have suggested that exposure of cells to modified ECM can alter gene expression [63] and promote inflammation [64], the effects of TE modification have also been examined in vivo in mice.

\section{MATERIALS AND METHODS}

\section{Materials}




\section{ACCEPTED MANUSCRIPT}

Recombinant full-length TE was expressed and purified from an E. coli expression system as described previously [65]. All other chemicals were from Sigma-Aldrich unless stated otherwise. Milli-Q grade water (Millipore Advantage A10; Merck-Millipore, Billerica, MA, USA) was used to prepare buffers, and all reaction mixtures were treated with Chelex-100 resin (Bio-Rad, Hercules, CA, USA) to remove trace metal ions. ONOOH was synthesized using a two-phase system from isoamyl nitrite and $\mathrm{H}_{2} \mathrm{O}_{2}$, as described previously [66], with residual $\mathrm{H}_{2} \mathrm{O}_{2}$ removed by treatment with $\mathrm{MnO}_{2}$. Stock solutions of the $\mathrm{ONOOH}$ were stored at $-80^{\circ} \mathrm{C}$ until use, and used immediately after thawing, with unused material discarded. The concentration of $\mathrm{ONOOH}$ solutions was determined spectrophotometrically using an extinction coefficient of $1705 \mathrm{M}^{-1} \mathrm{~cm}^{-1}$ [67]. Decomposed oxidant solutions (indicated as $\mathrm{dONOOH}$ ) were used as controls for any residual materials from the synthesis, with these being prepared by overnight incubation at $37^{\circ} \mathrm{C}$ in $0.1 \mathrm{M}$ phosphate buffer, $\mathrm{pH}$ 7.4. Stock solutions of $\mathrm{ONOOH}$ were prepared in freshly prepared $0.1 \mathrm{M} \mathrm{NaOH}$ just before use in experiments, with low volumes of the oxidant added to strongly buffered solutions (100 mM phosphate buffer, $\mathrm{pH}$ 7.4) to prevent significant changes in $\mathrm{pH}$. Reaction mixtures were prepared by rapidly adding $\mathrm{ONOOH}$ to centrifuge tubes with vortexing to ensure rapid homogenous reaction.

SDS-PAGE and Western blotting

TE was diluted in $100 \mathrm{mM}$ phosphate buffer, $\mathrm{pH} 7.4$, and exposed to $\mathrm{ONOOH}$ in either the absence or presence of $\mathrm{NaHCO}_{3}(25 \mathrm{mM}$ final concentration, to give physiological levels of $\mathrm{CO}_{2}$ ), for $20 \mathrm{~min}$ at $21^{\circ} \mathrm{C}$. With this incubation time complete consumption of $\mathrm{ONOOH}$ occurs [68]. Samples for analysis were prepared using NuPAGE ${ }^{\circledR}$ LDS Sample Buffer (4x) and NuPAGE ${ }^{\circledR}$ Sample Reducing Agent (10x) as described by the manufacturer (Invitrogen), 


\section{ACCEPTED MANUSCRIPT}

with reduction carried out for $10 \mathrm{~min}$ at $70{ }^{\circ} \mathrm{C}$. Protein samples were loaded at $1.5-5 \mu \mathrm{g}$ per lane, with HiMark ${ }^{\mathrm{TM}}$ pre-stained protein standards $(31-460 \mathrm{kDa})$ used as a reference and to indicate approximate masses. SDS-PAGE was carried out on $1 \mathrm{~mm} \mathrm{NuPAGE}{ }^{\circledR} \mathrm{NOVEX}^{\circledR} 3$ 8\% Tris-Acetate Gels using NuPAGE ${ }^{\circledR}$ Tris-Acetate SDS Running Buffer at 150 V (40-55 $\mathrm{mA} / \mathrm{gel}$ ) for $1 \mathrm{~h}$. After electrophoretic separation, proteins were visualized using either Coomassie ${ }^{\circledR}$ R-250 or silver staining, or subjected to Western blotting.

For Coomassie staining, the gels were fixed and stained using $0.1 \%(\mathrm{w} / \mathrm{v})$ Coomassie $\mathrm{R}-250$ in $40 \%(\mathrm{v} / \mathrm{v})$ ethanol and $10 \%(\mathrm{v} / \mathrm{v})$ acetic acid and microwaved for $1 \mathrm{~min}$ on high power followed by $15 \mathrm{~min}$ incubation at $21^{\circ} \mathrm{C}$ on an orbital shaker. The staining solution was then removed and the gels were destained using $10 \%(\mathrm{v} / \mathrm{v})$ ethanol and $7.5 \%(\mathrm{v} / \mathrm{v})$ acetic acid in water with microwave exposure for $1 \mathrm{~min}$. Gels were then incubated on an orbital shaker until a colorless background was achieved, and scanned using a standard flat bed scanner $[49,50]$.

For silver staining, the gels were fixed in a solution containing $50 \%(\mathrm{v} / \mathrm{v})$ methanol and $10 \%(\mathrm{v} / \mathrm{v})$ acetic acid for $30 \mathrm{~min}$, then incubated in 5\%(v/v) methanol for $15 \mathrm{~min}$ and 3 times for $5 \mathrm{~min}$ in $\mathrm{H}_{2} \mathrm{O}$ to rehydrate the gels. The gels were then incubated in freshly prepared $0.02 \%(\mathrm{w} / \mathrm{v})$ sodium thiosulfate for $2 \mathrm{~min}$, washed for 2 min with $\mathrm{H}_{2} \mathrm{O}$ and stained with $0.2 \%$ (w/v) silver nitrate for $25 \mathrm{~min}$. Unbound silver nitrate was removed by washing for $5 \mathrm{~min}$ with $\mathrm{H}_{2} \mathrm{O}$. Gels were developed in a solution containing $3 \%(\mathrm{w} / \mathrm{v})$ sodium carbonate, $0.0004 \%(\mathrm{w} / \mathrm{v})$ sodium thiosulfate and $0.05 \%(\mathrm{v} / \mathrm{v})$ formaldehyde until the desired staining intensity was achieved, with development terminated by treatment with $1.4 \%(\mathrm{w} / \mathrm{v})$ EDTA $[49,50]$.

For Western blotting experiments, proteins were electroblotted onto nitrocellulose membranes using an iBlot ${ }^{\circledR}$ transfer apparatus (Invitrogen). Membranes were blocked with $1 \%(\mathrm{w} / \mathrm{v})$ casein in phosphate buffered saline with Tween $20(\mathrm{PBST})$ for $1 \mathrm{~h}$ and then probed 


\section{ACCEPTED MANUSCRIPT}

with primary monoclonal (mAb) or polyclonal antibodies $(\mathrm{pAb})$ diluted in blocking solution overnight at $4{ }^{\circ} \mathrm{C}$ (mouse anti-elastin mAb [C-terminal domain 36, 1:1000 dilution]; mouse anti-elastin mAb [BA-4 clone, Sigma-Aldrich, 1:2000 dilution]; rabbit anti-3-nitroTyr pAb [Merck-Millipore, 1:2000 dilution]). Membranes were rinsed 3 times for 5 min with PBST before incubation with an appropriate secondary HRP-conjugated IgG antibodies (1:5000 dilution) for $1 \mathrm{~h}$ (anti-rabbit pAb [NA934, GE]; anti-mouse pAb [sc-2005, Santa Cruz, Dallas, TX, USA]). In order to reduce background, unbound HRP was removed by extensive washing, 4 times for 10 min with PBST and twice with water for 10 min followed by detection of immune complexes with Western Lightning Plus ECL reagent (Perkin Elmer). Chemiluminescent images were acquired using an Image Quant LAS 4000 system (GE Healthcare), reference protein markers were visualized in normal brightfield and aligned to chemiluminescent images.

High performance/Ultra high performance liquid chromatography (HPLC/UHPLC)

Loss of parent amino acids and formation of 3-nitroTyr was quantified using two different UHPLC/HPLC methods. For analysis of total amino acids (method (a)) control and modified protein was carried out using acid hydrolysis with methanesulfonic acid as described previously [69], using commercially available amino acid mixtures to generate standard curves and pre-column derivatization with the fluorescent tag $o$-phthaldialdehyde. The tagged amino acids were separated on a Shimadzu Nexera UHPLC system and eluted by gradient elution with buffer A consisting of $100 \mathrm{mM}$ sodium acetate, $\mathrm{pH} 5.3$, in water with $2.5 \%(\mathrm{v} / \mathrm{v})$ tetrahydrofuran and 20\% (v/v) methanol, and buffer B (100 mM sodium acetate, $\mathrm{pH} 5.3$, in water with $2.5 \%(\mathrm{v} / \mathrm{v})$ tetrahydrofuran and $80 \%(\mathrm{v} / \mathrm{v})$ methanol). The gradient protocol consisted of an increase from $100 \%$ buffer A to $25 \%$ buffer B over 6 min, elution with this 


\section{ACCEPTED MANUSCRIPT}

mixture for $1 \mathrm{~min}$, then a gradient to $62 \%$ buffer B over $0.5 \mathrm{~min}$, elution with $62 \%$ buffer B for $2.5 \mathrm{~min}$, then a gradient to $100 \%$ buffer B over 2 min, elution with $100 \%$ buffer B for $1 \mathrm{~min}$, then a gradient to $100 \%$ buffer $\mathrm{A}$ over $0.5 \mathrm{~min}$, and re-equilibration with buffer $\mathrm{A}$ for a further $3.5 \mathrm{~min}$. The tagged amino acids were detected with a Shimadzu, RF-20A fluorescence detector with $\lambda_{\mathrm{Ex}}=340 \mathrm{~nm}$ and $\lambda_{\mathrm{Em}}=440 \mathrm{~nm}$.

3-NitroTyr generation on oxidant-treated and control protein (prepared as described above) was examined (method (b)) using samples containing $100 \mu \mathrm{g}$ protein in $130 \mu \mathrm{L} 0.1 \mathrm{M}$ PBS. These were incubated with $20 \mu \mathrm{L}$ of pronase solution $\left(1 \mathrm{mg} \mathrm{mL}^{-1}\right.$; protein/enzyme ratio 5:1) and incubated for $24 \mathrm{~h}$ at $50{ }^{\circ} \mathrm{C}$ in an incubator to release free amino acids. Undigested peptides and remaining enzyme were removed by filtration (Nanosep ${ }^{\circledR} 3 \mathrm{~K}$ cut off centrifugal filtration devices, $13300 \mathrm{~g}, 30 \mathrm{~min}$ ). Control samples containing only pronase were also prepared to determine the contribution of pronase auto-digestion to the free amino acid pool; these values are reported, but not subtracted, as they may over-estimate the extent of autodigestion in the presence of substrate. Standard stock solutions of parent Tyr and 3-nitroTyr, (either $100 \mu \mathrm{M}$ or $1 \mathrm{mM}$ ) were also prepared then diluted as required. The filtrates from protein digestion were injected onto a Kromasil C18, $5 \mu \mathrm{m}, 250 \times 4.6 \mathrm{~mm}$ column together with a Pelliguard LC 18 guard column and components separated using a gradient elution system on a Shimadzu HPLC system (SIL-20AC HT, LC-10AT, CTO-10AS; Shimdazu, Kyoto, Japan) equipped with a UV-VIS detector (SPD-10A) connected in series with a multichannel Coularray electrochemical detector (5020 guard cell, $6210 \mathrm{Hi}-\mathrm{E}$ four sensor assembly; ESA, Chelmsford, MA, USA) with the column maintained at $30{ }^{\circ} \mathrm{C}$ with a flow rate of $1 \mathrm{~mL} \mathrm{~min}^{-1}$. The elution gradient consisted of $100 \%$ buffer $\mathrm{A}$ ( $50 \mathrm{mM}$ citric acid in water, $\mathrm{pH} 2.3$, with $2 \%[\mathrm{v} / \mathrm{v}]$ acetonitrile) for $3 \mathrm{~min}$, then a gradient to $70 \%$ buffer $\mathrm{B}(50 \mathrm{mM}$ citric acid in water, $\mathrm{pH} 2.3$, with $20 \%$ [v/v] acetonitrile) over $17 \mathrm{~min}$, a gradient to $100 \%$ buffer B over $5 \mathrm{~min}, 100 \%$ buffer B for $10 \mathrm{~min}$, then re-equilibration to $100 \%$ buffer A over 


\section{ACCEPTED MANUSCRIPT}

$10 \mathrm{~min}$. Detection and quantification of tyrosines (o-Tyr, $m$-Tyr, $p$-Tyr) was carried out using their UV absorption at $280 \mathrm{~nm}$. These compounds were also detected electrochemically using a 12-channel Coularray electrochemical detector, but only 3-nitroTyr was quantified using this method. Electrode potentials were adjusted (50, 150, 250, 300, 350, 450, 500, 550, 620, $700,810,840 \mathrm{mV}$ respectively) to achieve stepwise oxidation of compounds, with the integrations carried out on the peak intensities for three channels (dominant channel, and the channels before and after this) summed. Under these condition 3-nitroTyr was detected solely in channels $10-12$, with a retention time of $\sim 30 \mathrm{~min}$.

\section{Mass spectroscopic detection of protein cross-links}

$20 \mu \mathrm{g}$ of TE (control or exposed to $\mathrm{ONOOH}$ as described above) was dissolved in $20 \mu \mathrm{L} 8 \mathrm{M}$ urea, $50 \mathrm{mM}$ Tris- $\mathrm{HCl}$ at $\mathrm{pH}$ 8.0. Two microliters of dithiothreitol (DTT, $450 \mathrm{mM}$ ) was then added and incubated for $45 \mathrm{~min}$ at $21^{\circ} \mathrm{C}$. Alkylation was carried out adding iodoacetamide (IAM, $4 \mu \mathrm{L}, 500 \mathrm{mM}$ ), followed by incubation for $60 \mathrm{~min}$ at $21{ }^{\circ} \mathrm{C}$ in the dark. The sample was then divided into two fractions, for trypsin digestion in ${ }^{16} \mathrm{O}$ - and ${ }^{18} \mathrm{O}$-water, respectively, followed by solid-phase extraction on activated StageTip C18 reversed-phase discs as

reported elsewhere [70]. The ${ }^{16} \mathrm{O}$ - and ${ }^{18} \mathrm{O}$-labelled samples were then dried down (Speedvac ${ }^{\mathrm{TM}}$ concentrator, 3 mins) and re-suspended in $10 \mu \mathrm{L} \mathrm{H}_{2}{ }^{16} \mathrm{O}$ and $\mathrm{H}_{2}{ }^{18} \mathrm{O}$, respectively. These samples were mixed at a 1:1 ratio immediately prior to analysis [70].

Mass spectrometric analysis of peptide samples was carried out on an EASY nLC 1000 chromatograph (Thermo Fischer Scientific) with an EASY-spray column (Pepmap Thermo Fischer Scientific; $3 \mu \mathrm{m}, \mathrm{C} 1815 \mathrm{~cm} \times 75 \mu \mathrm{m})$ coupled online to an Orbitrap Fusion mass spectrometer (Thermo Fischer Scientific). Separation was performed with a flow rate of 250 $\mathrm{nL}$ min- 1 and gradient of solvents $\mathrm{A}(0.1 \% \mathrm{FA})$ and $\mathrm{B}(80 \% \mathrm{ACN}$ and $0.1 \% \mathrm{FA})$ and data acquisition was performed as previously described [70], with high-energy collisional 


\section{ACCEPTED MANUSCRIPT}

dissociation fragmentation (28\% collision energy and 120000 resolution, Orbitrap detection).

MassAI (version April 2017, University of Southern Denmark) was used for identification and verification of cross-linked peptides in MS/MS with the following settings: fixed (cysteine carbamidomethylation) and variable (methionine oxidation, tyrosine oxidation) modifications; maximum number of missed cleavages 2; parent mass tolerance 10 ppm; MS2 peak tolerance $0.02 \mathrm{~m} / \mathrm{z}$. The search criteria included intra-protein and xlink modified peptides. Positive candidates were re-evaluated manually by score and spectral analysis. Quantification of the selected cross-linked peptides was performed manually based on the ion intensities originating from the corresponding peptide spectrum matches in three experimental replicates.

\section{Immunohistochemical staining of human atherosclerotic lesions}

Arteriae femuralis and aortae abdominalis samples were obtained within $12 \mathrm{~h}$ from 3 subjects who died of cerebral haemorrhage. Lesion severity was classified according to Stary and coworkers [71] and ranged here from microscopically normal to thickened intima (type IIIII). Samples were immediately frozen in a cryostat (Microm HM500 OM; Microm, Walldorf, Germany), supported by tissue freezing medium (Tissue Tec OCT-compound; Miles, Elkhard, Ind., USA) [72]. Five $\mu \mathrm{m}$ serial cryosections were collected on glass slides, air-dried $\left(2 \mathrm{~h}, 21^{\circ} \mathrm{C}\right)$, fixed in acetone $\left(5 \mathrm{~min}, 21^{\circ} \mathrm{C}\right.$ and stored at $-70{ }^{\circ} \mathrm{C}$ until analysis. Approval of the institutional ethics committee was obtained for this study (Medical University Graz, EK-number: 29-464 ex 16/17). All methods were performed in accordance with the relevant guidelines and regulations.

For immunohistochemistry and double immunofluorescence, sections were thawed, fixed in acetone $\left(21^{\circ} \mathrm{C}, 5 \mathrm{~min}\right)$, then rehydrated in PBS followed by blocking using Ultra $\mathrm{V}$ 


\section{ACCEPTED MANUSCRIPT}

block for 10 min (Lab Vision, Fremont, CA, USA). For immunohistochemistry, sections were incubated $\left(21^{\circ} \mathrm{C}, 30 \mathrm{~min}\right)$ with either mouse anti-elastin mAb (clone 10B8, Abcam, 1:100 dilution) or with rabbit anti-3-nitroTyr pAb (IgG; Merck-Millipore, 1:100 dilution). Detection of the signal was performed with the UltraVision system from LabVision, based on a peroxidase-labelled biotin-streptavidin system. Control experiments were performed by omission of the primary $\mathrm{Ab}$ or by preincubation of rabbit anti-3-nitroTyr with a $12.5-25$ fold molar excess of nitrated tropoelastin or native tropoelastin. The competitor was preincubated with the primary antibody for $60 \mathrm{~min}$ before adding to the section. The slides were developed with aminoethylcarbazole (LabVision) $\left(21^{\circ} \mathrm{C}, 4 \mathrm{~min}\right)$, counterstained with Mayer's hemalum and mounted with Kaiser's glycerolgelatine (Merck). Oil red stain of serial sections was performed as described [72]. Pictures were taken with a Leica CM 6000B microscope equipped with an Olympus DP72 camera. For double immunofluorescence, sections were incubated with mouse anti-elastin mAb (clone 10B8, Abcam, 1:100 dilution) followed by goat anti-mouse cyanine-2 (Cy-2)-labeled pAb (mouse IgG, Jackson Dianova, 1:300 dilution). Afterwards slides were incubated with rabbit anti-3-nitroTyr pAb (rabbit IgG; Merck-Millipore, 1:100 dilution) followed by goat anti-rabbit Cy-3-labeled pAb (IgG, 1:300 dilution) [73]. Sections were mounted with Moviol (Calbiochem-Novabiochem, La Jolla, USA) and analyzed using a confocal laser-scanning microscope operating in sequential mode (Leica SP2; Leica Lasertechnik GmbH, Heidelberg, Germany), with the $488 \mathrm{~nm}$ laser line used for Cy-2 excitation, and the $543 \mathrm{~nm}$ line for Cy-3. Emission detection used 500-540 nm (green staining) for Cy-2, and 560-620 nm (red staining) for Cy-3. Controls were performed by omitting of the primary antibodies or by replacing them with non-immune rabbit IgG (Sigma-Aldrich) or non-immune mouse IgG (Sigma-Aldrich). PBS was used for all washing steps between the incubations and Dako antibody diluent for antibody dilutions. All incubation steps were performed in dark moisture chambers at $21^{\circ} \mathrm{C}$. 
Statistics

Statistical analyses were performed using GraphPad Prism (version 5.0f; GraphPad Software, San Diego, CA, USA). One-way ANOVA with post hoc analysis using Dunnett's multiple comparison test was used for HPLC and ELISA data, and Tukey's multiple comparison test for cell adhesion data. Two-way ANOVA with Bonferroni's post hoc test was performed to compare samples with and without $\mathrm{HCO}_{3}{ }^{-} / \mathrm{CO}_{2}$. Data are representative of at least three independent experiments, with $\mathrm{p}<0.05$ considered significant. Details of the tests used in particular analyses are given in the appropriate figure legends.

\section{RESULTS}

Effect of $\mathrm{ONOOH}$ and $\mathrm{ONOOCO}_{2}^{-}$on tropoelastin (TE) structure

$\mathrm{TE}(5 \mu \mathrm{M})$ was exposed to increasing concentrations of reagent $\mathrm{ONOOH}$ (molar ratios 1 250 fold over protein, i.e. $5 \mu \mathrm{M}-1.25 \mathrm{mM}$ ) for $20 \mathrm{mins}$ at $21^{\circ} \mathrm{C}$, before being loaded on to SDS-PAGE gels. After separation, the gels were developed with Coomassie ${ }^{\circledR}$ R-250, or silver staining, and subsequently imaged. Under these conditions, exposure of TE to high molar ratios of $\mathrm{ONOOH}$ resulted in a decrease in staining of the parent protein band at $\sim 60$ $\mathrm{kDa}$, and a dose-dependent detection of bands assigned to dimers and higher oligomers (Fig. 1A; Coomassie-stained gels not shown). The apparent masses of these species do not correspond to exact multiples of that of the parent protein, consistent with increased interactions with SDS; this is a well-established phenomenon with proteins of high hydrophobicity (e.g. membrane proteins [74]). Significant dimer formation was detected with equimolar or higher levels of oxidant (i.e. an average of a single modification event per protein molecule). With increasing oxidant doses, formation of trimers, tetramers and 


\section{ACCEPTED MANUSCRIPT}

smeared bands at even higher masses were detected. With very high oxidant excesses, significant amounts of the protein did not enter the gel from the loading wells, resulting in a decreased extent of total staining, though there was an increase in staining at lower molecular masses $(<60 \mathrm{kDa})$ indicative of protein fragmentation. Decomposed ONOOH even at the highest concentrations used (250-fold excess; indicated as 250x dec.) did not induce any significant changes compared to the untreated controls (Fig. 1).

Western blotting of separated protein samples, exposed to oxidant in an identical manner, was carried out using two mAbs that recognize well-defined elastin epitopes. The first of these recognizes the C-terminal domain 36 [75], the second mAb (clone BA-4), recognises a repeat sequence (Val-Gly-Val-Ala-Pro-Gly), which is a chemoattractant for fibroblasts and monocytes. Both mAbs recognized native TE at a molecular mass of $\sim 60 \mathrm{kDa}$ (Fig. 1B,C), but the staining intensity of the TE band decreased with increasing $\mathrm{ONOOH}$ concentration, indicating significant perturbation of the protein structure and loss of the specific epitopes recognised by these antibodies. The decomposed oxidant at the highest concentration used, did not show any significant differences compared to the control, untreated protein (Fig. 1B,C). In contrast to the data obtained with silver staining (Fig. 1A), no significant staining was detected at higher molecular masses with either antibody (Fig. 1B,C), suggesting that the dimer and higher oligomers formed in response to oxidant treatment have significantly perturbed structures compared to the monomer.

The effect of $\mathrm{ONOOCO}_{2}^{-}$, relative to identical concentrations of $\mathrm{ONOOH}$ on TE, was examined by including $25 \mathrm{mM} \mathrm{HCO}_{3}{ }^{-}$in the reaction buffers to give physiological levels of $\mathrm{CO}_{2}$. As shown in Fig. 2A, the presence of $\mathrm{HCO}_{3}{ }^{-}$decreased the extent of loss of parent protein as detected by Coomassie-staining, and also against the loss of epitope recognition by the antibody BA-4 (Fig. 2B), consistent with $\mathrm{ONOOCO}_{2}^{-}$inducing less marked damage and alterations to the protein. As expected the presence of $\mathrm{HCO}_{3}{ }^{-}$had no effect of the behaviour 


\section{ACCEPTED MANUSCRIPT}

of the decomposed oxidant (dONOOH) (data not shown). Western blotting using a mAb against the nitration product 3-nitroTyr showed a dose-dependent increase in staining of the

parent protein band with increasing $\mathrm{ONOOH}$ levels, with significant staining detected at a 10fold or higher molar excess of ONOOH over protein (Fig. 2C). No staining was detected with decomposed ONOOH (data not shown). This detection of 3-nitroTyr on the parent protein was accompanied by increased staining of material at both higher masses (detected as broad smearing), and also on specific fragments at lower mass. In particular three discrete bands with approximate molecular masses of $\sim 50, \sim 35$ and $\sim 15 \mathrm{kDa}$ were detected (Fig. 2), consistent with selective cleavage of TE by $\mathrm{ONOOH}$ at particular sites in the protein sequence. These fragments were less readily observed with either Coomassie staining or Western blotting experiments using the BA-4 mAb. The presence of $\mathrm{HCO}_{3}{ }^{-}$appeared to decrease the extent of 3-nitroTyr detection both on the parent protein band and on the observed fragments. These data indicate significant modification of Tyr residues present on TE, with formation of 3-nitroTyr, but the concentration of these species cannot be determined from these gels.

\section{Quantification of amino acid residues in recombinant human TE on ONOOH exposure}

In order to determine the extent of modification of Tyr residues, and 3-nitroTyr formation, as well as potential modification at other residues, amino acid analysis was carried out using HPLC with either acid (data not shown) or enzymatic hydrolysis (Fig. 3A). This technique allows quantification of all of the common amino acids with the exception of cysteine/cystine and proline residues, with the pairs of glutamine/glutamic acid and asparagine/aspartic acid eluting as single peaks as a result of hydrolysis of the amide to the corresponding carboxylic acids. The resulting data were normalized against isoleucine to compensate for any protein 


\section{ACCEPTED MANUSCRIPT}

loss during sample preparation and variable efficiency of hydrolysis. For the non-modified samples, comparison of this experimental data with the theoretical amino acid content of TE (Supplementary Table 1), gave identical ratios (within experimental error) of each amino acids (relative to isoleucine) to that expected, the exception of aspartic acid which elutes very close to the void volume, and whose quantification was affected by this. These data confirm the high purity of the protein, and the absence of any Trp and Met residues in the protein. Comparison of the data obtained from the untreated samples compared to those treated with $\mathrm{ONOOH}$, in either the absence or presence of $\mathrm{HCO}_{3}{ }^{-}$, indicated that Tyr was the only amino acid whose concentration was significantly affected by ONOOH treatment, with a significant loss of this amino acid detected with a 25 -fold or greater molar oxidant excess over protein using the enzymatic method (Fig. 3A), or with a 50-fold, or greater, molar oxidant excess using the acid hydrolysis technique (data not shown). No significant difference was detected in the extent of Tyr loss between the samples exposed to $\mathrm{ONOOH}$ in the absence or presence of $\mathrm{HCO}_{3}{ }^{-}$, though there was a trend towards a greater loss in the absence of $\mathrm{HCO}_{3}{ }^{-}$(Fig. $\left.3 \mathrm{~A}\right)$. The extent of 3-nitroTyr formation was examined using the enzymatic hydrolysis method (Fig. 3B), with a dose-dependent increase in the yield of this protein modification product detected with increasing levels of $\mathrm{ONOOH}$, in the absence of $\mathrm{HCO}_{3}{ }^{-}$, up to a 50 -fold or greater molar oxidant excess over protein. At higher molar excesses of $\mathrm{ONOOH}$ the levels of this product reached a plateau, and then subsequently decreased with very high oxidant concentrations. A significant extent of formation of this material, relative to the control (untreated) or decomposed oxidant-treated samples, was detected with a 5-fold molar excess of oxidant. For experiments carried out in the presence of $\mathrm{ONOOH}$ and $\mathrm{HCO}_{3}{ }^{-}$, significant levels of 3-nitroTyr were also detected, with this becoming significant with a 10-fold molar excess of oxidant over protein, with a plateau concentration of 3-nitroTyr detected at a 25fold or higher levels of oxidant. However, the absolute levels of 3-nitroTyr detected in the 


\section{ACCEPTED MANUSCRIPT}

presence of $\mathrm{HCO}_{3}{ }^{-}$were significantly lower than those detected in its absence, consistent with the gel data (Fig. 2C). These data are consistent with Tyr residues being the major target of ONOOH in TE, with near 100\% loss of parent Tyr detected at very high $\mathrm{ONOOH}$ levels.

\section{Identification of protein cross-links in recombinant human TE on ONOOH exposure}

The detection of higher mass species of TE after exposure to $\mathrm{ONOOH}$ on the gels (Fig. 1A) is consistent with the presence of covalent non-reducible bonds between TE molecules. The significant consumption of Tyr residues and the known formation of cross-linked species from this amino acid (e.g. di-tyrosine, and cross-links involving quinones derived from Tyr [76]) prompted an examination of the nature of the cross-links formed in $\mathrm{ONOOH}$-treated TE. The presence of cross-links was investigated by making use of the addition mass differences present in cross-linked peptides containing two carboxyl termini after protein digestion by trypsin in $\mathrm{H}_{2}{ }^{18} \mathrm{O}$ compared to $\mathrm{H}_{2}{ }^{16} \mathrm{O}$ [70,77]). Thereby distinctive peaks differing by $4 \mathrm{Da}$ appear in the mass spectra (i.e. $+8 \mathrm{Da}$ for $\mathrm{H}_{2}{ }^{18} \mathrm{O}$ digested samples for cross-linked species, compared to $+4 \mathrm{Da}$ for non-cross-linked peptides as a result of the incorporation of 4 ${ }^{18} \mathrm{O}$ atoms at the two $\mathrm{C}$-termini of the cross-linked peptide compared to $2{ }^{18} \mathrm{O}$ atoms at the single terminal carboxylate of non-cross-linked species). Using this approach evidence has been obtained for inter- and / or intra-molecular Tyr-Tyr species in the treated TE.

With TE samples exposed to 1, 2.5 and 25-fold molar excess of ONOOH consistent evidence was found for a Tyr-Tyr (Y-Y) cross-link between the peptides LPGGYGLPYTTGK LPYGYGPGGVAGAAGK (cross-link \#1, Fig. 4A), with the crosslinked residues highlighted in bold. This cross-linked peptide displayed the expected - 2.01 Da difference compared to the sum of the two parent peptides due to formation of a Y-Y crosslink, with the theoretical mass (2754.407) matching closely to the experimental mass 


\section{ACCEPTED MANUSCRIPT}

(2754.405; 2.49 ppm mass error). The intensity of this cross-linked peptide increased significantly from 1- to 25-fold molar excess of ONOOH (Supplementary Figure 1). The MS/MS spectrum of this species (Fig. 4A) revealed several fragment ions that retain the cross-link site ( $\mathrm{y}_{5}-\mathrm{y}_{10}$ ions for the $\beta$ peptide and $\mathrm{y}_{14}-\mathrm{y}_{15}, \mathrm{~b}_{5}-\mathrm{b}_{9}$ for the $\alpha$ peptide), providing strong evidence for the presence of the $\mathrm{Y}-\mathrm{Y}$ cross-link. This cross-linked peptide comprises sequential sections of the protein sequence (i.e. the amino acid sequence is LPGGYGLPYTTGKLPYGYGPGGVAGAAGK, with tryptic cleavage occurring after the K residue in the middle of this sequence. It is unclear (due to the absence of a high resolution structure of the protein) whether this is an intra-molecular cross-link arising from a close spatial alignment of the two Tyr residues as a result of a loop in the secondary structure, or whether this is an inter-molecular cross-link.

Strong evidence was also obtained for a cross-link between Tyr (Y) residues in two peptides with sequence LPYGYGPGGVAGAAGK (i.e. LPYGYGPGGVAGAAGK LPYGYGPGGVAGAAGK, cross-link \#2, Fig. 4B,C). This Y-Y link appears in two sets of cross-linked peptides containing different modifications on the second (non cross-linked) Tyr residue (i.e. at $Y$ in LPYGYGPGGVAGAAGK). In the first species (Fig. 4B) this Tyr is subjected to oxidation $(+15.99$, i.e. hydroxylation to give DOPA $)$ and nitration $(+44.985,3-$ nitroTyr), respectively, in the two peptide chains (experimental mass 2926.429 Da compared to theoretical value of $2926.43 \mathrm{Da} ; 2.77 \mathrm{ppm}$ mass difference). In the second species (Fig. 4C) the corresponding Tyr residue is nitrated in both peptide chains (experimental mass 2955.408 Da compared to theoretical value of $2955.414 \mathrm{Da} ; 2.03 \mathrm{ppm}$ mass difference). The intensity of both cross-linked peptides was highest in the sample treated with 25-fold molar excess (Fig. S4). As both these species contain two copies of the same peptide, it is concluded that these must correspond to an inter-molecular cross-link. 


\section{ACCEPTED MANUSCRIPT}

A cross-link was also detected between AGYPTGTGVGPQAAAAAAAK

LPGGYGLPYTTGKLPYGYGPGGVAGAAGK (cross-link \#3, Fig. 4D). This species (experimental mass 4481.285 Da compared to theoretical mass 4481.272 Da; 6.3 ppm mass difference) was detected with oxidation (+ 15.99, hydroxylation) at the second Tyr in the second peptide (i.e. at $Y$ in LPGGYGLPYTTGKLPYGYGPGGVAGAAGK), a residue involved in cross-link \#2. The MS/MS spectrum of this cross-linked peptide shows that the $\mathrm{b}_{5}-\mathrm{b}_{8}$ fragment ions for the $\alpha$ peptide (longer peptide, in blue) retain the cross-links, as well as the $b_{6}-b_{7}$ ions for the $\beta$ peptide (shorter peptide, in red). Whether this is an inter- or intramolecular cross-link species remains to be established, due to the absence of a high-resolution structure of this protein. The abundance of this cross-linked peptide is highest in 25 -fold molar excess of $\mathrm{ONOOH}$, followed by 1- and 2.5-fold molar excess (Fig. S4).

In vivo detection of 3-nitroTyr and modified elastin in human arterial and aortic lesions

As elastin is highly abundant in major arteries and evidence has been presented for changes in this protein during atherogenesis [31,32], and to be associated with areas of lipid deposition $[33,34,55]$, we examined in human atherosclerotic lesions, the potential colocalization of both elastin and 3-nitroTyr epitopes and lipid pools (as evidenced by Oil Red staining).

Fig. 5 (A-C) shows an arteria femuralis with a heavily thickened intima. Pronounced staining for elastin is present in the media, in particular in elastic membranes, while faint staining for elastin is present deep in the intima close to the borderline of the media (Fig. 5A). Faint staining for 3-nitroTyr is present at the endothelial layer (Fig. 5B). While no staining for 3-nitroTyr was found in the media, abundant staining for 3-nitroTyr occurs in the deeper intima region as well as in the middle portion of the intima (Fig. 5B). The latter area is heavily invaded with foam cells detected by oil red staining (Fig. 5C). These cells 


\section{ACCEPTED MANUSCRIPT}

(monocytes/macrophages) primarily account for the pronounced 3-nitroTyr staining (Fig.

5B). To confirm the specificity of the anti 3-nitroTyr for nitrated epitopes in human arterial and aortic material (Fig. 5B, 5D), the pAb was preabsorbed with an excess of either nitrated tropoelastin or native (unmodified) tropoelastin before use with serial sections of human aorta abdominalis. While nitrated tropoelastin diminished immunoreactivity to background staining levels (Fig. 5E), native tropoelastin, used as a competitor, did not affect staining for 3nitroTyr epitopes (Fig. 5F vs. Fig. 5D).

Sections were also examined by double immunofluoresecence for the presence of elastin using the mAb 10B8, which recognises human elastin, and 3-nitroTyr epitopes using a rabbit anti-3-nitroTyr pAb (Fig. 6). The anti-elastin antibody, as expected, provided evidence for the presence of high levels of elastin underneath the endothelial layer (Fig. 6A). The staining for elastin shows the characteristic layered structure of elastic laminae. Limited fluorescence was detected deeper in the tissue sections. Corresponding experiments examining the presence of 3-nitroTyr epitopes also provided evidence, in line with previous observations [46,48-50], for significant levels of this material underneath the endothelial layer (Fig. 6B). Merging of these images (Fig. 6C) showed pronounced staining for elastin and 3nitroTyr epitopes in close proximity with partial colocalization within tissue sections from the lesions. This data are consistent with damage to both elastin, and other matrix components, with damage particularly localized to the lamina closest to the luminal surface. Control experiments using non-immune mouse or rabbit IgG showed no artifactual staining.

\section{DISCUSSION}




\section{ACCEPTED MANUSCRIPT}

The studies reported here examined the hypothesis that TE the precursor of the major ECM elastin, would be a major target for modification by the major inflammatory oxidants $\mathrm{ONOOH}$ and $\mathrm{ONOOCO}_{2}^{-}$due to its unique amino acid composition, that this would result in the formation of high yields of 3-nitroTyr, and that these modifications would result in altered structural and functional properties of the protein, with the latter tested both in vitro and in vivo. These studies complement previous studies on this protein (which used very high excesses of oxidant $[59,60]$ ), other isolated ECM proteins (perlecan, laminin, fibronectin [4850,78]), as well as basement membrane extracts, cell culture-derived materials and tissue extracts which contain mixtures of these species $[63,78]$.

It has been shown that exposure of TE to $\mathrm{ONOOH}$ has a dramatic effect on the composition and structure of the protein, with significant levels of 3-nitroTyr detected with very low levels of $\mathrm{ONOOH}$, and formation of modified forms of the protein (both aggregates and fragments) as detected by silver staining, Western blotting with two different antibodies and also by MS analysis. These changes are detected with molar excesses of $\mathrm{ONOOH}$ in the range 1-5 fold, or greater, thus even single hits (i.e. equimolar amounts of $\mathrm{ONOOH}$ to target) appear to be capable of inducing significant changes to the structure of this protein. Of particular interest was the observed loss of recognition of the C-terminal domain of TE, by the corresponding antibody, as this region has been linked with a number functional properties including elastin-fibre assembly and cell binding $[4,21,22,75,79]$. However, sequence data for TE indicates that there are no Tyr residues in the protein near the Cterminus (the closest is approximately 50 residues away; Fig. 8), but this does not preclude a close spatial alignment of a critical Tyr residue that is far removed from the C-terminus. Resolution of this issue awaits a high-resolution structure of the protein. It should however also be noted that this C-terminal region contains the sole disulfide (cystine) cross-link in the protein and it is known that $\mathrm{ONOOH}$ can oxidize such residues ([62,80]; L. Carroll, M. 


\section{ACCEPTED MANUSCRIPT}

Ignasiak, unpublished data) and this may give rise to the decreased antibody recognition.

Protein bound 3-nitroTyr was detected on both the main parent TE band, and also on fragments with distinct molecular mass. The masses of these fragments are similar to those that arise from thrombin and kallikrein cleavage [81]. Kallikrein and thrombin are serum proteases capable of degrading TE with thrombin cleaving at Arg 515 (and to lesser extent at Lys 152) whereas kallikrein recognises Arg 515 (at the end of domain 25) and Arg 564 (within domain 26) [82,83]. Such enzymatic cleavage gives three major fragments with masses of 45, 31 and $13 \mathrm{kDa}$. The region of TE between these cleavage sites contains domain 26 , which is known to play a major role in coacervation and correct elastic fibre assembly [83].

The sensitivity of TE to modification by $\mathrm{ONOOH}$ is likely to arise, at least in part, from the unusual parent amino acid composition of this protein, which contains no free Cys residues (though it does contain 2 Cys residues that form an intrachain disulfide bond [84]), Met, Trp, or His residues. Each of these species, together with Tyr, is a known, or potential, target for the inflammatory oxidants $\mathrm{ONOOH}$ and $\mathrm{ONOOCO}_{2}{ }^{-}[62,85]$. The absence of these other reactive residues was predicted to result in Tyr residues being quantitatively the most important major target, though limited reaction at the single disulphide (cystine) may also occur $[62,85]$. This has not been quantified, but is likely to account for only a modest amount of the added $\mathrm{ONOOH}$ (see also below). The amino acid analysis confirms the marked selectivity for Tyr residue modification, with this being the only amino acid, of those analysed (i.e. excluding cystine) depleted significantly on ONOOH exposure. The loss of Tyr was mirrored by the formation of 3-nitroTyr residues (detected both by UPLC analysis and by MS to a more limited extent), with both Tyr loss and 3-nitroTyr formation occurring to a lower extent in the presence of $\mathrm{HCO}_{3}{ }^{-}$. This is likely to be due to the formation of $\mathrm{ONOOCO}_{2}^{-}$via reaction of $\mathrm{ONOO}^{-}$with $\mathrm{CO}_{2}$, with this species being less efficient at both 


\section{ACCEPTED MANUSCRIPT}

oxidising Tyr, and generating 3-nitroTyr. This decreased reactivity of $\mathrm{ONOOCO}_{2}{ }^{-}$is consistent with previous data with other matrix proteins [48-50], but may be specific to such materials as previous studies have reported increased levels of nitration in the presence of $\mathrm{CO}_{2}[86,87]$. In both the absence or presence of $\mathrm{HCO}_{3}{ }^{-}$, a dose-dependent increase in 3nitroTyr was observed, followed by a plateau, and a decrease in the case of $\mathrm{ONOOH}$ alone. These data suggest that 3-nitroTyr is modified or lost via additional reactions, with this potentially involving formation of 3,5-dinitroTyr, an established secondary oxidation product of 3-nitroTyr. Reaction at Phe residues, of which there are 16 in TE, is also a possibility at these high oxidant levels, with this giving 4-nitrophenylalanine as well as $p$-, $m$ - and $o$ tyrosine $[88,89]$, but this does not appear to be a major fate of the added ONOOH, as no significant loss of parent Phe was detected. The possible formation and quantification of 3,5dinitroTyr has not been examined, as this is only likely to be of relevance with high oxidant excesses, that are of limited, or no, biological relevance.

Further information as to the significance of 3-nitroTyr formation in the modification of TE has been obtained by determining the percentage conversion of Tyr to 3-nitroTyr (Fig. 7A), and the percentage conversion of $\mathrm{ONOOH}$ to 3-nitroTyr (Fig. 7B). With regard to the former it can be seen that up to $15 \%$ of the Tyr residues present in TE are converted to 3nitroTyr at a 50-fold molar ratio of $\mathrm{ONOOH}$ to TE. As there are $15 \mathrm{Tyr}$ residues per mole of TE this equates, on average, to a total of 2 modified Tyr residues per protein molecule with this damage likely to be spread over multiple Tyr residues, when exposed to $\mathrm{ONOOH}$, and a total of 1 modified Tyr per protein with a similar molar excess of $\mathrm{ONOOCO}_{2}^{-}$(i.e. $\mathrm{ONOOH}$ in presence of $\mathrm{HCO}_{3}{ }^{-}$). Similar analyses indicate that approximately a 12-fold molar excess of ONOOH over TE results on average to one modified Tyr per protein. These values are likely to overestimate the amount of $\mathrm{ONOOH}$ needed to induce these levels of modification, as a result of secondary loss of 3-nitroTyr as outlined above. 


\section{ACCEPTED MANUSCRIPT}

With regard to the extent of conversion of $\mathrm{ONOOH}$ to 3-nitroTyr, the maximum extent of conversion of oxidant to this product peaks at approximately $8 \%$ for the system in the absence of $\mathrm{HCO}_{3}{ }^{-}$, and 5\% in its presence (Fig. 7B). As with Fig. 7A, this plot shows a marked inverted "U" shape consistent with the occurrence of further/secondary reactions at high oxidant concentrations. Whilst these percentage conversion values may initially appear low, it should be noted that this is a very high value when compared to data for reaction of this oxidant with other biological targets $[48-50,61,62,78]$. A low percentage conversion is typically detected for this oxidant as a result of the occurrence of the rapid spontaneous conversion of $\mathrm{ONOOH}$ to nitrite $\left(\mathrm{NO}_{2}{ }^{-}\right)$and nitrate $\left(\mathrm{NO}_{3}{ }^{-}\right)$and, where Tyr residues are the target, the requirement for two successive reactions to generate 3-nitroTyr, via initial formation of the Tyr phenoxyl radical, and then subsequent reaction of this species with $\mathrm{NO}_{2}$. This results in a low overall product yield. Clearly the extent of these (and other) competing pathways for $\mathrm{ONOOH}$ are highly dependent on the reaction conditions and reactant concentrations, but the high detected levels of conversion with the relatively modest concentrations of TE used in these experiments $(10 \mu \mathrm{M})$ suggest that 3-nitroTyr formation from Tyr is a quantitatively important reaction. Furthermore, given the very high level of 30$55 \%$ of mature elastin in the aorta, it may also be a major process in vivo; this is currently being examined.

The detection of aggregates of TE with low levels of ONOOH exposure by SDSPAGE and also MS is consistent with oxidation of Tyr residues to Tyr phenoxyl radicals. Subsequent reaction of these radicals with $\mathrm{NO}_{2} \cdot$ are likely to be the major route to 3-nitroTyr, however dimerization of two phenoxyl radicals to give di-tyrosine also appears to be a major fate of these species, with this pathway proposed to be the major route to (irreversible) crosslink formation. The MS data has provided evidence consistent with both inter- and intramolecular cross-links. Although two of the detected cross-links can be attributed to either 


\section{ACCEPTED MANUSCRIPT}

inter- or intra-molecular linkages, the detection of a cross-link between the Tyr residues of two identical peptides of sequence LPYGYGPGGVAGAAGK provides convincing evidence of covalent inter-molecular protein cross-links.

Of particular interest is the observation that the two Tyr residues involved in crosslink \#1 (i.e. the two Tyr residues highlighted in bold in the sequence LPGGYGLPYTTGKLPYGYGPGGVAGAAGK) are also involved in both the other crosslinks that have been detected. Furthermore, oxidation and nitration (to give 3-nitroTyr) were also detected within this sequence (at $Y$ in the above sequence).

All of these cross-links occur within one part of the protein sequence (Fig. 8; Tyr residues involved in cross-links are Y217, Y221, Y228 and Y244, with oxidation / nitration also detected at Y221 and Y230; numbering using the complete protein sequence from UniProtKB entry P15502) suggesting that this section of the molecule must both react readily and rapidly with the oxidant, and be a highly accessible (or flexible) region on the protein surface, in order to allow rapid cross-linking and oxidation / nitration to occur. This suggestion is supported by the detection of cross-links with very low levels of ONOOH (equimolar or greater concentrations). The Tyr residues involved in these cross-linked peptides and the oxidations / nitrations are indicated in Fig. 8.

The ability of TE to self-assemble (coacervate), is a critical factor in its biological function, and it is clear that exposure to even low levels (equimolar concentrations) of oxidant can modulate this process. This may arise from rapid and efficient modification at a limited number of Tyr residues within the protein with this resulting in efficient inter-protein crosslinks. The formation of intra-protein cross-links may also alter coacervation via modification of the 3-dimensional structure of the monomer protein. Experiments performed by Akhtar et al $[59,60]$ indicate that $\mathrm{ONOOH}$ affects elastic fibre assembly and cell binding, with abnormal coacervation behaviour of oxidised TE detected at low temperatures when 


\section{ACCEPTED MANUSCRIPT}

compared to native TE. Furthermore, human retinal pigment endothelial cells incubated with oxidised TE were unable to incorporate the oxidised material into existing fibres [59]. Disorganized elastic fibre composition and reduced artery wall integrity (as evidenced by a greater extent of fragmented internal elastic laminae) is a known feature in cardiovascular disease in both humans [37] and many mouse strains [90] (though not apparently elastin heterozygous knockout mice [91]), and together these data suggest that this might be due to either modification by ONOOH of newly-synthesised TE, which then does not incorporate (or incorporates incorrectly) into existing fibres, or $\mathrm{ONOOH}$-induced changes to mature elastin. A previous study has also reported elevated levels of 4-hydroxynonenal-modified elastin in human atherosclerotic lesions, consistent with elastin being modified by material derived from oxidized lipids [19].

The data reported here for the human atherosclerotic lesions is consistent with the presence of significant levels of 3-nitroTyr, with the staining for this epitope appearing to occur primarily in the vicinity of lipid-laden macrophage cells. This is consistent with previous data [48], and suggests that activated macrophages are a major (though not necessarily the only) source of $\mathrm{ONOOH}$ in such lesions, and implicates the inducible nitric oxide enzyme of these cells as a major driver of oxidant damage. The colocalization of the 3nitroTyr epitopes with (at least in part) elastin and elastic lamina structures is consistent with the previous reports (see above) of elastin modification in human atherosclerotic lesions, and a potential role for such elastin (and other ECM) modifications in the accumulation of lipid deposits within the artery wall $[34,55]$. One limitation of the current data is that the time course (i.e. sequence) of these events cannot be established, due to the difficulty in obtaining material from the earliest stages of human lesion development. Thus, it remains to be established whether lipid accumulation in macrophages is a driver of subsequent matrix modifications, or whether activation of macrophages induces modification to elastin (and 


\section{ACCEPTED MANUSCRIPT}

other matrix materials) with these modified matrix molecules enhancing subsequent ingress, retention and modification of lipid-containing particles (e.g. low-density lipoproteins) in the artery wall, with subsequent uptake by macrophages, via scavenger receptors to give foam cells.

In conclusion, these data indicate that isolated TE is a major and highly susceptible target for the inflammatory oxidant $\mathrm{ONOOH}$, with this resulting in marked and selective conversion of the Tyr residues in this protein to 3-nitroTyr and dityrosine cross-links. This selectivity appears to arise from the absence of other $\mathrm{ONOOH}$-reactive residues, and gives very high extents of conversion of Tyr to 3-nitroTyr (with up to 2 Tyr residues modified per

mole of protein), and $\mathrm{ONOOH}$ to this product (up to $8 \%$ conversion), as well as significant cross-link formation. These levels of conversion of Tyr to 3-nitroTyr are much higher than detected with other matrix proteins studied to date (e.g. perlecan, fibronectin and laminin [4850], though whether the extent of modification correlates strongly with functional effects and biological consequences has yet to be determined. Furthermore, extrapolation of this in vitro data to in vivo situations is unlikely to be sensible. Exposure of TE to ONOOH also generates inter- (and possibly intra-) molecular cross-links, as well as the formation of specific fragments that contain 3-nitroTyr residues; these changes occur with very low levels of oxidant (1-5 fold molar excesses), consistent with a possible pathological relevance. This conclusion is supported by the detection of 3-nitroTyr in human atherosclerotic lesions and its co-localization with both lipid pools and elastin.

\section{ACKNOWLEDGEMENTS}

We are grateful for financial support from the Novo Nordisk Foundation (Laureate Research Grant NNF13OC0004294 to MJD), the Danish Research Foundation (Grant: DFF-701400047 to MJD), the Australian Research Council (through the Centres of Excellence Scheme, CE0561607, and Discovery Programs DP0988311). The Orbitrap Fusion mass spectrometer 


\section{ACCEPTED MANUSCRIPT}

used in this study was granted by the Velux Foundation. The Danish Research Foundation, Nordic Bioscience A/S and Technical University of Denmark are acknowledged for a jointly funded $\mathrm{PhD}$ scholarship to MM. 


\section{ACCEPTED MANUSCRIPT}

\section{REFERENCES}

[1] Debelle, L.; Tamburro, A. M. Elastin: Molecular description and function. Int. J. Biochem. Cell Biol. 31 (1999) 261-272.

[2] Mithieux, S. M.; Weiss, A. S. Elastin. In: David, A. D. P.; John, M. S., eds. Advances in protein chemistry: Academic Press; 2005: 437-461.

[3] Wise, S. G.; Weiss, A. S. Tropoelastin. Int. J. Biochem. Cell Biol. 41 (2009) 494-497.

[4] Yeo, G. C.; Keeley, F. W.; Weiss, A. S. Coacervation of tropoelastin. Adv. Colloid Interface Sci. 167 (2011) 94-103.

[5] Davidson, J. M. Smad about elastin regulation. Am. J. Respir. Cell. Mol. Biol. 26 (2002) 164-166.

[6] Curran, M. E.; Atkinson, D. L.; Ewart, A. K.; Morris, C. A.; Leppert, M. F.; Keating, M. T. The elastin gene is disrupted by a translocation associated with supravalvular aortic stenosis. Cell 73 (1993) 159-168.

[7] Olsen, D. R.; Fazio, M. J.; Shamban, A. T.; Rosenbloom, J.; Uitto, J. Cutis laxa: Reduced elastin gene expression in skin fibroblast cultures as determined by hybridizations with a homologous cdna and an exon 1-specific oligonucleotide. J. Biol. Chemc 263 (1988) 6465-6467.

[8] Hinek, A.; Wilson, S. E. Impaired elastogenesis in hurler disease: Dermatan sulfate accumulation linked to deficiency in elastin-binding protein and elastic fiber assembly. Am. J. Pathol. 156 (2000) 925-938.

[9] Hinek, A.; Smith, A. C.; Cutiongco, E. M.; Callahan, J. W.; Gripp, K. W.; Weksberg, R. Decreased elastin deposition and high proliferation of fibroblasts from Costello syndrome 


\section{ACCEPTED MANUSCRIPT}

are related to functional deficiency in the 67-kd elastin-binding protein. Am. J. Human Genet. $66(2000) 859-872$.

[10] Li, D. Y.; Brooke, B.; Davis, E. C.; Mecham, R. P.; Sorensen, L. K.; Boak, B. B.;

Eichwald, E.; Keating, M. T. Elastin is an essential determinant of arterial morphogenesis. Nature 393 (1998) 276-280.

[11] Li, D. Y.; Faury, G.; Taylor, D. G.; Davis, E. C.; Boyle, W. A.; Mecham, R. P.; Stenzel, P.; Boak, B.; Keating, M. T. Novel arterial pathology in mice and humans hemizygous for elastin. J. Clin. Invest. 102 (1998) 1783-1787.

[12] Zarins, C. K.; Xu, C.; Glagov, S. Atherosclerotic enlargement of the human abdominal aorta. Atherosclerosis 155 (2001) 157-164.

[13] Masuda, H.; Zhuang, Y. J.; Singh, T. M.; Kawamura, K.; Murakami, M.; Zarins, C. K.; Glagov, S. Adaptive remodeling of internal elastic lamina and endothelial lining during flow-induced arterial enlargement. Arterioscl. Thromb. Vasc. Biol. 19 (1999) 2298-2307.

[14] Masawa, N.; Glagov, S.; Zarins, C. K. Quantitative morphologic study of intimal thickening at the human carotid bifurcation: I. Axial and circumferential distribution of maximum intimal thickening in asymptomatic, uncomplicated plaques. Atherosclerosis 107 (1994) 137-146.

[15] Masawa, N.; Glagov, S.; Zarins, C. K. Quantitative morphologic study of intimal thickening at the human carotid bifurcation: II. The compensatory enlargement response and the role of the intima in tensile support. Atherosclerosis 107 (1994) 147-155.

[16] Isik, F. F.; Clowes, A. W.; Gordon, D. Elastin expression in a model of acute arterial graft rejection. Transplantation 58 (1994) 1246-1251. 


\section{ACCEPTED MANUSCRIPT}

[17] Nikkari, S. T.; Jarvelainen, H. T.; Wight, T. N.; Ferguson, M.; Clowes, A. W. Smooth muscle cell expression of extracellular matrix genes after arterial injury. Am. J. Pathol. 144 (1994) 1348-1356.

[18] Fritze, O.; Romero, B.; Schleicher, M.; Jacob, M. P.; Oh, D. Y.; Starcher, B.; Schenke-Layland, K.; Bujan, J.; Stock, U. A. Age-related changes in the elastic tissue of the human aorta. J. Vasc. Res. 49 (2012) 77-86.

[19] Zarkovic, K.; Larroque-Cardoso, P.; Pucelle, M.; Salvayre, R.; Waeg, G.; Negre-

Salvayre, A.; Zarkovic, N. Elastin aging and lipid oxidation products in human aorta. Redox Biol. 4 (2015) 109-117.

[20] Gayral, S.; Garnotel, R.; Castaing-Berthou, A.; Blaise, S.; Fougerat, A.; Berge, E.; Montheil, A.; Malet, N.; Wymann, M. P.; Maurice, P.; Debelle, L.; Martiny, L.; Martinez, L. O.; Pshezhetsky, A. V.; Duca, L.; Laffargue, M. Elastin-derived peptides potentiate atherosclerosis through the immune Neu1-PI3kgamma pathway. Cardiovasc. Res. 102 (2014) 118-127.

[21] Vrhovski, B.; Weiss, A. S. Biochemistry of tropoelastin. Eur. J. Biochem. 258 (1998) $1-18$.

[22] Broekelmann, T. J.; Kozel, B. A.; Ishibashi, H.; Werneck, C. C.; Keeley, F. W.; Zhang, L. J.; Mecham, R. P. Tropoelastin interacts with cell-surface glycosaminoglycans via its cooh-terminal domain. J. Biol. Chem. 280 (2005) 40939-40947.

[23] Tu, Y.; Weiss, A. S. Glycosaminoglycan-mediated coacervation of tropoelastin abolishes the critical concentration, accelerates coacervate formation, and facilitates spherule fusion: Implications for tropoelastin microassembly. Biomacromolecules 9 (2008) 17391744. 


\section{ACCEPTED MANUSCRIPT}

[24] Kielty, C. M. Elastic fibres in health and disease. Expert Rev. Mol. Med. 8 (2006) 123.

[25] Papke, C. L.; Yanagisawa, H. Fibulin-4 and fibulin-5 in elastogenesis and beyond: Insights from mouse and human studies. Matrix Biol. 37 (2014) 142-149.

[26] Hayes, A. J.; Lord, M. S.; Smith, S. M.; Smith, M. M.; Whitelock, J. M.; Weiss, A. S.; Melrose, J. Colocalization in vivo and association in vitro of perlecan and elastin. Histochem. Cell Biol. 136 (2011) 437-454.

[27] Toonkool, P.; Regan, D. G.; Kuchel, P. W.; Morris, M. B.; Weiss, A. S. Thermodynamic and hydrodynamic properties of human tropoelastin. Analytical ultracentrifuge and pulsed field-gradient spin-echo nmr studies. J. Biol. Chem. 276 (2001) 28042-28050.

[28] Kozel, B. A.; Rongish, B. J.; Czirok, A.; Zach, J.; Little, C. D.; Davis, E. C.; Knutsen, R. H.; Wagenseil, J. E.; Levy, M. A.; Mecham, R. P. Elastic fiber formation: A dynamic view of extracellular matrix assembly using timer reporters. J. Cell. Physiol. 207 (2006) 87-96.

[29] Fukuda, Y.; Nakazawa, N.; Yamanaka, N. Interactions of elastin and microfibrils in elastogenesis of human pulmonary fibroblasts in culture. Connect Tissue Res. 29 (1993) 301310.

[30] Brown-Augsburger, P.; Tisdale, C.; Broekelmann, T.; Sloan, C.; Mecham, R. P. Identification of an elastin cross-linking domain that joins three peptide chains. Possible role in nucleated assembly. J. Biol. Chem. 270 (1995) 17778-17783.

[31] Hosoda, Y.; Kawano, K.; Yamasawa, F.; Ishii, T.; Shibata, T.; Inayama, S. Agedependent changes of collagen and elastin content in human aorta and pulmonary artery. Angiology 35 (1984) 615-621. 


\section{ACCEPTED MANUSCRIPT}

[32] Katsuda, S.; Kaji, T. Atherosclerosis and extracellular matrix. J. Atheroscler. Thromb. 10 (2003) 267-274.

[33] Robert, L.; Robert, A. M.; Jacotot, B. Elastin-elastase-atherosclerosis revisited. Atherosclerosis 140 (1998) 281-295.

[34] Kramsch, D. M.; Franzblau, C.; Hollander, W. The protein and lipid composition of arterial elastin and its relationship to lipid accumulation in the atherosclerotic plaque. J. Clin. Invest. 50 (1971) 1666-1677.

[35] Davies, M. J.; Richardson, P. D.; Woolf, N.; Katz, D. R.; Mann, J. Risk of thrombosis in human atherosclerotic plaques: Role of extracellular lipid, macrophage, and smooth muscle cell content. Br. Heart J. 69 (1993) 377-381.

[36] Davies, M. J.; Thomas, A. C. Plaque fissuring - the cause of acute myocardial infarction, sudden ischaemic death and crescendo angina. Br. Heart J. 53 (1985) 363-373.

[37] Krettek, A.; Sukhova, G. K.; Libby, P. Elastogenesis in human arterial disease: A role for macrophages in disordered elastin synthesis. Arterioscler. Thromb. Vasc. Biol. 23 (2003) $582-587$.

[38] Shah, P. K.; Galis, Z. S. Matrix metalloproteinase hypothesis of plaque rupture: Players keep piling up but questions remain. Circulation 104 (2001) 1878-1880.

[39] Newby, A. C. Dual role of matrix metalloproteinases (matrixins) in intimal thickening and atherosclerotic plaque rupture. Physiol. Rev. 85 (2005) 1-31.

[40] Napoli, C.; Ignarro, L. J. Nitric oxide and pathogenic mechanisms involved in the development of vascular diseases. Arch. Pharmacol. Res. 32 (2009) 1103-1108.

[41] Radi, R. Nitric oxide, oxidants, and protein tyrosine nitration. Proc. Natl. Acad. Sci. USA 101 (2004) 4003-4008. 


\section{ACCEPTED MANUSCRIPT}

[42] Xia, Y.; Zweier, J. L. Superoxide and peroxynitrite generation from inducible nitric oxide synthase in macrophages. Proc. Natl. Acad. Sci. USA 94 (1997) 6954-6958.

[43] Carballal, S.; Bartesaghi, S.; Radi, R. Kinetic and mechanistic considerations to assess the biological fate of peroxynitrite. Biochim. Biophys. Acta 1840 (2014) 768-780.

[44] Koppenol, W. H.; Bounds, P. L.; Nauser, T.; Kissner, R.; Ruegger, H. Peroxynitrous acid: Controversy and consensus surrounding an enigmatic oxidant. Dalton Trans. 41 (2012) 13779-13787.

[45] Yamakura, F.; Ikeda, K.; Matsumoto, T.; Taka, H.; Kaga, N. Formation of 6nitrotryptophan in purified proteins by reactive nitrogen species: A possible new biomarker. Int. Congress Series 1304 (2007) 22-32.

[46] Beckmann, J. S.; Ye, Y. Z.; Anderson, P. G.; Chen, J.; Accavitti, M. A.; Tarpey, M. M.; White, C. R. Extensive nitration of protein tyrosines in human atherosclerosis detected by immunohistochemistry. Biol. Chem. Hoppe Seyler 375 (1994) 81-88.

[47] Leeuwenburgh, C.; Hardy, M. M.; Hazen, S. L.; Wagner, P.; Oh-ishi, S.; Steinbrecher, U. P.; Heinecke, J. W. Reactive nitrogen intermediates promote low density lipoprotein oxidation in human atherosclerotic intima. J. Biol. Chem. 272 (1997) 1433-1436.

[48] Kennett, E. C.; Rees, M. D.; Malle, E.; Hammer, A.; Whitelock, J. M.; Davies, M. J. Peroxynitrite modifies the structure and function of the extracellular matrix proteoglycan perlecan by reaction with both the protein core and the heparan sulfate chains. Free Radic. Biol. Med. 49 (2010) 282-293.

[49] Degendorfer, G.; Chuang, C. Y.; Hammer, A.; Malle, E.; Davies, M. J. Peroxynitrous acid induces structural and functional modifications to basement membranes and its key component, laminin. Free Radic. Biol. Med. 89 (2015) 721-733. 


\section{ACCEPTED MANUSCRIPT}

[50] Degendorfer, G.; Chuang, C. Y.; Kawasaki, H.; Hammer, A.; Malle, E.; Yamakura, F.; Davies, M. J. Peroxynitrite-mediated oxidation of plasma fibronectin. Free Radic. Biol. Med. 97 (2016) 602-615.

[51] Thomson, L.; Tenopoulou, M.; Lightfoot, R.; Tsika, E.; Parastatidis, I.; Martinez, M.;

Greco, T. M.; Doulias, P. T.; Wu, Y.; Tang, W. H.; Hazen, S. L.; Ischiropoulos, H. Immunoglobulins against tyrosine-nitrated epitopes in coronary artery disease. Circulation $126(2012) 2392-2401$.

[52] Rees, M. D.; Kennett, E. C.; Whitelock, J. M.; Davies, M. J. Oxidative damage to extracellular matrix and its role in human pathologies. Free Radic. Biol. Med. 44 (2008) 1973-2001.

[53] Kennett, E. C.; Chuang, C. Y.; Degendorfer, G.; Whitelock, J. M.; Davies, M. J. Mechanisms and consequences of oxidative damage to extracellular matrix. Biochem. Soc. Trans. 39 (2011) 1279-1287.

[54] Chuang, C. Y.; Degendorfer, G.; Davies, M. J. Oxidation and modification of extracellular matrix and its role in disease. Free Radic. Res. 48 (2014) 970-989.

[55] Kramsch, D. M.; Hollander, W. The interaction of serum and arterial lipoproteins with elastin of the arterial intima and its role in the lipid accumulation in atherosclerotic plaques. J. Clin. Invest. 52 (1973) 236-247.

[56] Kovacic, J. C.; Moreno, P.; Nabel, E. G.; Hachinski, V.; Fuster, V. Cellular senescence, vascular disease, and aging: Part 2: Clinical vascular disease in the elderly. Circulation 123 (2011) 1900-1910.

[57] Pasquali-Ronchetti, I.; Baccarani-Contri, M.; Fornieri, C.; Mori, G.; Quaglino Jr, D. Structure and composition of the elastin fibre in normal and pathological conditions. Micron $24(1993) 75-89$. 


\section{ACCEPTED MANUSCRIPT}

[58] Basalyga, D. M.; Simionescu, D. T.; Xiong, W.; Baxter, B. T.; Starcher, B. C.; Vyavahare, N. R. Elastin degradation and calcification in an abdominal aorta injury model: Role of matrix metalloproteinases. Circulation 110 (2004) 3480-3487.

[59] Akhtar, K.; Broekelmann, T. J.; Miao, M.; Keeley, F. W.; Starcher, B. C.; Pierce, R. A.; Mecham, R. P.; Adair-Kirk, T. L. Oxidative and nitrosative modifications of tropoelastin prevent elastic fiber assembly in vitro. J. Biol. Chem. 285 (2010) 37396-37404.

[60] Akhtar, K.; Broekelmann, T. J.; Song, H.; Turk, J.; Brett, T. J.; Mecham, R. P.; AdairKirk, T. L. Oxidative modifications of the c-terminal domain of tropoelastin prevent cell binding. J. Biol. Chem. 286 (2011) 13574-13582.

[61] Ischiropoulos, H.; Almehdi, A. B. Peroxynitrite-mediated oxidative protein modifications. FEBS Lett. 364 (1995) 279-282.

[62] Alvarez, B.; Radi, R. Peroxynitrite reactivity with amino acids and proteins. Amino Acids 25 (2003) 295-311.

[63] Chuang, C. Y.; Degendorfer, G.; Hammer, A.; Whitelock, J. M.; Malle, E.; Davies, M. J. Oxidation modifies the structure and function of the extracellular matrix generated by human coronary artery endothelial cells. Biochem. J. 459 (2014) 313-322.

[64] Adair-Kirk, T. L.; Senior, R. M. Fragments of extracellular matrix as mediators of inflammation. Int. J. Biochem. Cell Biol. 40 (2008) 1101-1110.

[65] Martin, S. L.; Vrhovski, B.; Weiss, A. S. Total synthesis and expression in escherichia coli of a gene encoding human tropoelastin. Gene 154 (1995) 159-166.

[66] Uppu, R. M.; Pryor, W. A. Synthesis of peroxynitrite in a two-phase system using isoamyl nitrite and hydrogen peroxide. Anal. Biochem. 236 (1996) 242-249. 


\section{ACCEPTED MANUSCRIPT}

[67] Bohle, D. S.; Hansert, B.; Paulson, S. C.; Smith, B. D. Biomimetic synthesis of the putative cytotoxin peroxynitrite, $\mathrm{ONOO}^{-}$, and its characterization as a tetramethylammonium salt. J. Am. Chem. Soc. 116 (1994) 7423-7424.

[68] Radi, R. Peroxynitrite reactions and diffusion in biology. Chem. Res. Toxicol. 11 (1998) 720-721.

[69] Hawkins, C. L.; Morgan, P. E.; Davies, M. J. Quantification of protein modification by oxidants. Free Radic. Biol. Med. 46 (2009) 965-988.

[70] Mariotti, M.; Leinisch, F.; Oersnes-Leeming, D. J.; Svensson, B.; Davies, M. J.; Hägglund, P. Mass spectrometry-based identification of cross-linked peptides in proteins subjected to photo-oxidation and chemical oxidation. J. Proteome Res. submitted (2017)

[71] Stary, H. C.; Chandler, A. B.; Dinsmore, R. E.; Fuster, V.; Glagov, S.; Insull, W., Jr.; Rosenfeld, M. E.; Schwartz, C. J.; Wagner, W. D.; Wissler, R. W. A definition of advanced types of atherosclerotic lesions and a histological classification of atherosclerosis. Arterioscler. Thromb. Vasc. Biol. 15 (1995) 1512-1531.

[72] Marsche, G.; Hammer, A.; Oskolkova, O.; Kozarsky, K. F.; Sattler, W.; Malle, E. Hypochlorite-modified high density lipoprotein, a high affinity ligand to scavenger receptor class B, type I, impairs high density lipoprotein-dependent selective lipid uptake and reverse cholesterol transport. J. Biol. Chem. 277 (2002) 32172-32179.

[73] Hammer, A.; Desoye, G.; Dohr, G.; Sattler, W.; Malle, E. Myeloperoxidasedependent generation of hypochlorite-modified proteins in human placental tissues during normal pregnancy. Lab. Invest. 81 (2001) 543-554.

[74] Rath, A.; Glibowicka, M.; Nadeau, V. G.; Chen, G.; Deber, C. M. Detergent binding explains anomalous SDS-PAGE migration of membrane proteins. Proc. Natl. Acad. Sci. USA $106(2009)$ 1760-1765. 


\section{ACCEPTED MANUSCRIPT}

[75] Brown-Augsburger, P.; Broekelmann, T.; Rosenbloom, J.; Mecham, R. P. Functional domains on elastin and microfibril-associated glycoprotein involved in elastic fibre assembly. Biochem. J. 318 (1996) 149-155.

[76] Houee-Levin, C.; Bobrowski, K.; Horakova, L.; Karademir, B.; Schoneich, C.; Davies, M. J.; Spickett, C. M. Exploring oxidative modifications of tyrosine: An update on mechanisms of formation, advances in analysis and biological consequences. Free Radic. Res. 49 (2015) 347-373.

[77] Liu, M.; Zhang, Z.; Zang, T.; Spahr, C.; Cheetham, J.; Ren, D.; Zhou, Z. S. Discovery of undefined protein cross-linking chemistry: A comprehensive methodology utilizing 18olabeling and mass spectrometry. Anal. Chem. 85 (2013) 5900-5908.

[78] Kennett, E. C.; Davies, M. J. Degradation of extracellular matrix by peroxynitrite/peroxynitrous acid. Free Radic. Biol. Med. 45 (2008) 716-725.

[79] Yeo, G. C.; Baldock, C.; Tuukkanen, A.; Roessle, M.; Dyksterhuis, L. B.; Wise, S. G.; Matthews, J.; Mithieux, S. M.; Weiss, A. S. Tropoelastin bridge region positions the cellinteractive c terminus and contributes to elastic fiber assembly. Proc. Natl. Acad. Sci. USA 109 (2012) 2878-2883.

[80] Carroll, L.; Davies, M. J.; Pattison, D. I. Reaction of low molecular mass organoselenium compounds (and their sulfur analogues) with inflammation-associated oxidants. Free Radic. Res. 49 (2015) 750-767.

[81] Gorbet, M. B.; Sefton, M. V. Biomaterial-associated thrombosis: Roles of coagulation factors, complement, platelets and leukocytes. Biomaterials 25 (2004) 5681-5703.

[82] Waterhouse, A.; Bax, D. V.; Wise, S. G.; Yin, Y.; Dunn, L. L.; Yeo, G. C.; Ng, M. K.; Bilek, M. M.; Weiss, A. S. Stability of a therapeutic layer of immobilized recombinant human tropoelastin on a plasma-activated coated surface. Pharm. Res. 28 (2011) 1415-1421. 


\section{ACCEPTED MANUSCRIPT}

[83] Jensen, S. A.; Vrhovski, B.; Weiss, A. S. Domain 26 of tropoelastin plays a dominant role in association by coacervation. J. Biol. Chem. 275 (2000) 28449-28454.

[84] Brown, P. L.; Mecham, L.; Tisdale, C.; Mecham, R. P. The cysteine residues in the carboxy terminal domain of tropoelastin form an intrachain disulfide bond that stabilizes a loop structure and positively charged pocket. Biochem. Biophys. Res. Commun. 186 (1992) $549-555$.

[85] Alvarez, B.; Ferrer-Sueta, G.; Freeman, B. A.; Radi, R. Kinetics of peroxynitrite reaction with amino acids and human serum albumin. J. Biol. Chem. 274 (1999) 842-848.

[86] Berlett, B. S.; Levine, R. L.; Stadtman, E. R. Carbon dioxide stimulates peroxynitritemediated nitration of tyrosine residues and inhibits oxidation of methionine residues of glutamine synthetase: Both modifications mimic effects of adenylylation. Proc. Natl. Acad. Sci. USA 95 (1998) 2784-2789.

[87] Tien, M.; Berlett, B. S.; Levine, R. L.; Chock, P. B.; Stadtman, E. R. Peroxynitritemediated modification of proteins at physiological carbon dioxide concentration: $\mathrm{Ph}$ dependence of carbonyl formation, tyrosine nitration, and methionine oxidation [in process citation]. Proc. Natl. Acad. Sci. USA 96 (1999) 7809-7814.

[88] van der Vliet, A.; O'Neill, C. A.; Halliwell, B.; Cross, C. E.; Kaur, H. Aromatic hydroxylation and nitration of phenylalanine and tyrosine by peroxynitrite. Evidence for hydroxyl radical production from peroxynitrite. FEBS Lett. 339 (1994) 89-92.

[89] Kaur, H.; Whiteman, M.; Halliwell, B. Peroxynitrite-dependent aromatic hydroxylation and nitration of salicylate and phenylalanine. Is hydroxyl radical involved? Free Radic. Res. 26 (1997) 71-82. 


\section{ACCEPTED MANUSCRIPT}

[90] Wang, Y.; Johnson, J. A.; Fulp, A.; Sutton, M. A.; Lessner, S. M. Adhesive strength of atherosclerotic plaque in a mouse model depends on local collagen content and elastin fragmentation. J. Biomech. 46 (2013) 716-722.

[91] Maedeker, J. A.; Stoka, K. V.; Bhayani, S. A.; Gardner, W. S.; Bennett, L.; Procknow,

J. D.; Staiculescu, M. C.; Walji, T. A.; Craft, C. S.; Wagenseil, J. E. Hypertension and decreased aortic compliance due to reduced elastin amounts do not increase atherosclerotic plaque accumulation in $\mathrm{LDLR}^{-/-}$mice. Atherosclerosis 249 (2016) 22-29. 


\section{ACCEPTED MANUSCRIPT}

\section{Highlights}

- The extracellular matrix determines tissue structure and function

- Peroxynitrous acid $(\mathrm{ONOOH})$ is formed at inflammatory sites including within the artery wall

- ONOOH induces Tyr nitration and crosslinking of tropoelastin (TE), and alters TE structure and function

- Extensive modification of TE occurs with equimolar and higher ONOOH concentrations

- Nitrated Tyr and elastin epitopes colocalize with macrophages in human atherosclerotic lesions 


\section{ACCEPTED MANUSCRIPT}

\section{FIGURE LEGENDS}

Fig. 1. Structural modifications to human recombinant tropoelastin (TE) induced by ONOOH. Recombinant TE $(5 \mu \mathrm{M})$ in $0.1 \mathrm{M}$ phosphate buffer $\mathrm{pH} 7.4$ was exposed to ONOOH (or $250 \mu \mathrm{M}$ decomposed oxidant, designated "250x dec.") at the molar ratios indicated for $20 \mathrm{~min}$ at $22{ }^{\circ} \mathrm{C}$ followed by separation on $3-8 \%$ Tris-acetate gels under reducing conditions with $2.5 \mu$ g protein loaded per lane. (A) Silver staining of protein gel. (Panels B,C) Western blotting on nitrocellulose membranes probed using the following mAbs raised against (B) TE C-terminal region, or (C) anti-elastin (clone BA-4). The positions of molecular mass markers (HMW) are shown for reference. Representative gel images are presented from multiple independent experiments.

Fig. 2. Structural and chemical modifications to human recombinant tropoelastin (TE) induced by $\mathrm{ONOOH}$ in the absence or presence of $\mathrm{HCO}_{3}{ }^{-}$. Recombinant TE $(5 \mu \mathrm{M})$ in $0.1 \mathrm{M}$ phosphate buffer $\mathrm{pH} 7.4$ was exposed to $\mathrm{ONOOH}$ at the molar ratios indicated, in the absence (-) or presence (+) of $25 \mathrm{mM} \mathrm{HCO}_{3}$, for $20 \mathrm{~min}$ at $22{ }^{\circ} \mathrm{C}$ followed by separation on $3-8 \%$ Tris-acetate gels under reducing conditions. (A) Protein staining using Coomassie Blue. $(\mathrm{B}, \mathrm{C})$ Western blotting on nitrocellulose membranes probed using (B) the anti-TE mAb (clone BA4), or (C) a anti-3-nitroTyr pAb (\#10189540). The position of the molecular mass markers (HMW) are shown for reference. Lanes marked "SDS 100x" are TE samples (as above) pretreated with SDS to unfold the protein, before treatment with a 100-fold molar excess of ONOOH. These lanes therefore represent maximal epitope exposure / staining. Representative gel images from multiple independent experiments. 


\section{ACCEPTED MANUSCRIPT}

Fig. 3. Quantification of the loss of parent tyrosine, and formation of 3-nitroTyr, on treatment of human recombinant tropoelastin (TE) with $\mathrm{ONOOH}$ in the absence or presence of $\mathrm{HCO}_{3}^{-}$, as assessed by HPLC. TE $(10 \mu \mathrm{M}$ in $0.1 \mathrm{M}$ phosphate buffer, $\mathrm{pH} 7.4)$ was treated with ONOOH or decomposed oxidant (500 $\mu \mathrm{M}$, designated "d 500") at the molar ratios indicated, in the absence (black bars) or presence (grey bars) of $25 \mathrm{mM} \mathrm{HCO}_{3}{ }^{-}$for $20 \mathrm{~min}$ at $22{ }^{\circ} \mathrm{C}$. The protein was then digested enzymatically using pronase, and subjected to HPLC analysis as described in the Materials and methods. Tyr levels resulting from the autodigestion of pronase in the absence of substrate are also reported, but not subtracted from the experimental values. Panel (A), loss of Tyr; panel (B), formation of 3-nitroTyr. Values are expressed as means \pm SEM from $n \geq 3$ independent experiments. Data were analyzed by 1 -way ANOVA (with $*, * *$ and $* * *$ indicating a significant difference compared to the controls at the $\mathrm{p}<$ $0.05,0.01$ and 0.001 levels respectively), or 2-way ANOVA (to examine the effect of the presence of $\mathrm{NaHCO}_{3}$; with \# indicating a significant difference compared to the absence of $\left.\mathrm{NaHCO}_{3}\right)$

Fig. 4. MS/MS spectra of Tyr-Tyr cross-linked peptides: A) triply charged cross-linked peptide LPGGYGLPYTTGK LPYGYGPGGVAGAAGK, with precursor m/z of 934.138; B) triply charged cross-linked peptide LPYGY-GPGGVAGAAGK LPYGY*GPGGVAGAAGK with precursor $\mathrm{m} / \mathrm{z}$ of 976.484 ; C) triply charged cross-linked peptide

LPYGY*GPGGVAGAAGK LPYGY*GPGGVAGAAGK with precursor m/z of 986.144; D) quintuply charged cross-linked peptide AGYPTGTGVGPQAAAAAAAK LPGGYGLPY-TTGKLPYGYGPGGVAGAAGK, with precursor m/z of 897.265. Red y and $\mathrm{b}$ fragments correspond to the $\alpha$ (longer) peptide, while blue $\mathrm{y}$ and $\mathrm{b}$ fragments correspond to the $\beta$ (shorter) peptide, and the $y$ and $b$ ions in black correspond to fragments that have the same mass for both $\alpha$ and $\beta$ peptides. Fragments in purple refer to neutral losses. * Indicates 


\section{ACCEPTED MANUSCRIPT}

the presence of a nitrated Tyr residue, and - indicates the presence of an oxidized Tyr residue (DOPA).

Fig. 5. Detection and localization of elastin (A), 3-nitroTyr epitopes (B) and lipid deposits (C) in human type II-III atherosclerotic lesions. Five $\mu \mathrm{m}$ frozen sections of human atherosclerotic lesions of arteria femuralis (A-C, autopsy material of a 80 -year-old female patient) and aorta abdominalis (D-F, autopsy material of a 74-year-old male patient) were incubated with anti-elastin mAb (clone 10B8, Abcam, dilution 1:100, A) or rabbit anti-3nitroTyr pAb (rabbit IgG, Merck-Millipore, dilution 1:100, B, D-F). Preincubation of the pAb was performed with a 25-fold molar excess of either nitrated tropoelastin (E) or unmodified tropoelastin (F). Immunoreactive signals were detected with an UltraVision system as described in the Methods section. The dotted line (A and B) marks the border between intima (left) and media (right). Lipid staining was performed with Oil Red (C).

Fig. 6. Co-localization of elastin epitopes and 3-nitroTyr in human type II-III atherosclerotic lesions of arteria femuralis (see Fig. 5A-C). The images show double immunofluorescence staining for elastin (panel A), 3-nitroTyr (B), and merged images (C) of $5 \mu \mathrm{m}$ frozen sections of human lesions, which were incubated with anti-elastin mAb (clone 10B8; 1:100 dilution) or rabbit anti-3-nitroTyr pAb (rabbit IgG, Merck-Millipore, 1:100). Labelled secondary goat anti-mouse $\mathrm{Cy}-2-\mathrm{pAb}$ (green), or goat anti-rabbit $\mathrm{Cy}-3$ (red)-labelled pAb was used for detection. Images were acquired as described in the experimental section. The $\mathrm{x} / \mathrm{y}$ dimensions of the scanned fields for $\mathrm{A}, \mathrm{B}$, and $\mathrm{C}$ are $100 \mu \mathrm{m}$ each.

Fig. 7. Quantitative assessment of the absolute levels of (Panel A) conversion of Tyr residues in tropoelastin (TE) to 3-nitroTyr, and (Panel B) ONOOH conversion to 3-nitroTyr with increasing molar ratios of $\mathrm{ONOOH}$ to TE. Data are recalculated from the experimental data 


\section{ACCEPTED MANUSCRIPT}

presented in Fig. 3 using the absolute levels of oxidant and parent and modified residues (corrected for recovery), the abundance of Tyr residues in the parent TE (15), and the relevant injection volumes. In both plots, the black bars indicate data obtained in the absence of $\mathrm{HCO}_{3}{ }^{-}$ , and grey bars data obtained in the presence of $25 \mathrm{mM} \mathrm{HCO}_{3}^{-}$. Values are expressed as means \pm SEM from $n \geq 3$ independent experiments. Data were analyzed by 1-way ANOVA (with * indicating a significant difference compared to controls at the $\mathrm{p}<0.05$ level and *** indicating $\mathrm{p}<0.001$ ), or 2-way ANOVA (to examine the effect of the presence of $\mathrm{NaHCO}_{3}$; with \# indicating a significant difference compared to the absence of $\mathrm{NaHCO}_{3}$ ).

Fig. 8. Primary sequence of isoform 3 ("canonical sequence") of human tropoelastin (TE) indicating sites of cross-links and modifications detected by MS analysis. Sequence data from UniProtKB, entry P15502, minus the N-terminal signal peptide (residues 1-26). The Tyr (Y) residues identified in inter- or intra-molecular cross-links are indicated in red text with yellow background, with the corresponding peptide sequences involved in these cross-links indicated by underscoring. The Tyr residue identified as either hydroxylated (probably DOPA) or nitrated (3-nitroTyr) species by MS analysis is indicated in blue text. Tyr residue (Y) 221, which is involved in these cross-links was also detected as an oxidized $(+15.99$; probably DOPA) species. The two Cys residues involved in the formation of the cystine disulphide bridge at the $\mathrm{C}$-terminus are indicated in green text. 


\section{ACCEPTED MANUSCRIPT}

\section{Highlights}

- The extracellular matrix determines tissue structure and function

- Peroxynitrous acid $(\mathrm{ONOOH})$ is formed at inflammatory sites including within the artery wall

- ONOOH induces Tyr nitration and crosslinking of tropoelastin (TE), and alters TE structure and function

- Extensive modification of TE occurs with equimolar and higher ONOOH concentrations

- Nitrated Tyr and elastin epitopes colocalize with macrophages in human atherosclerotic lesions 


\section{ACCEPTED MANUSCRIPT}
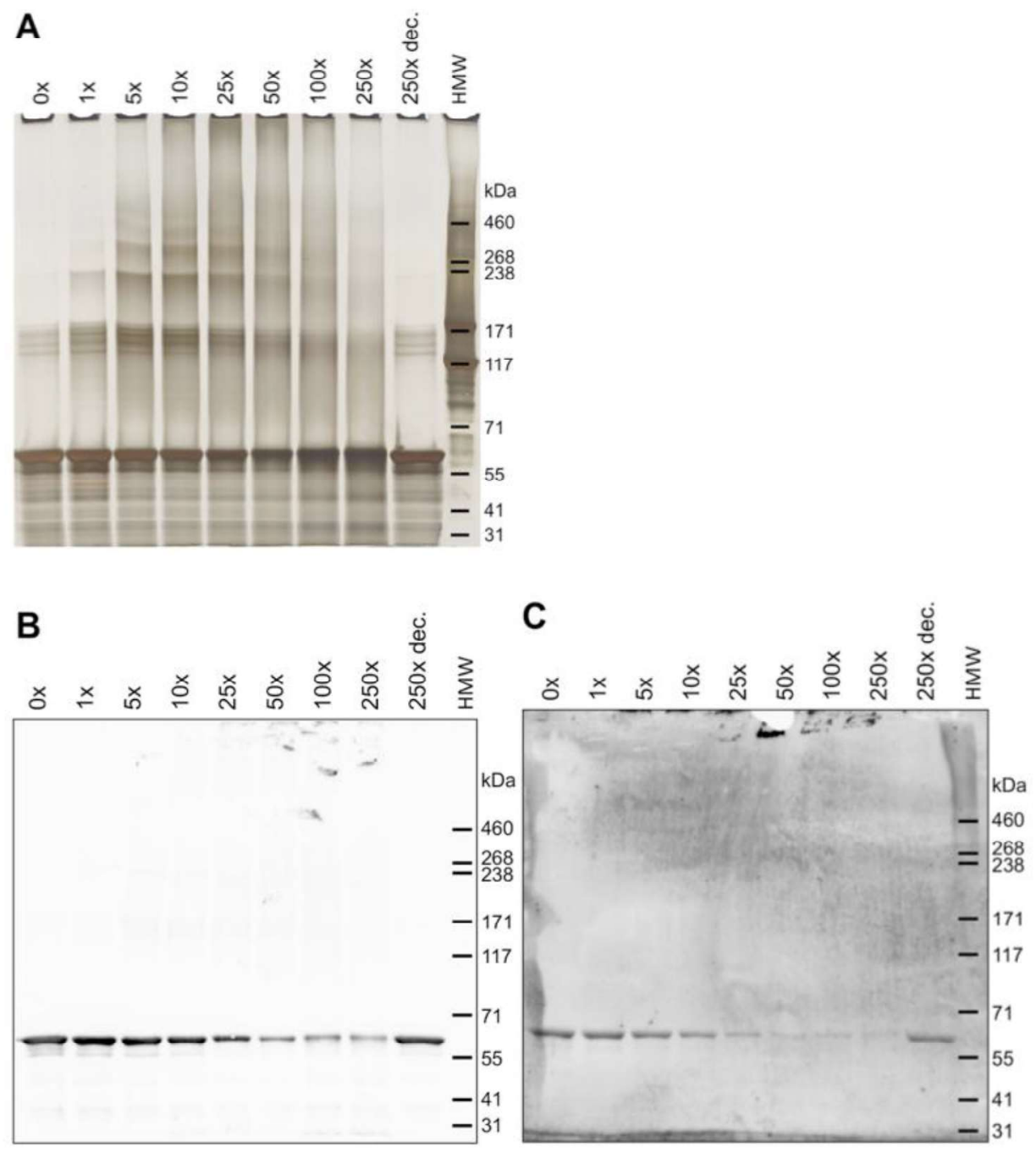


\section{ACCEPTED MANUSCRIPT}
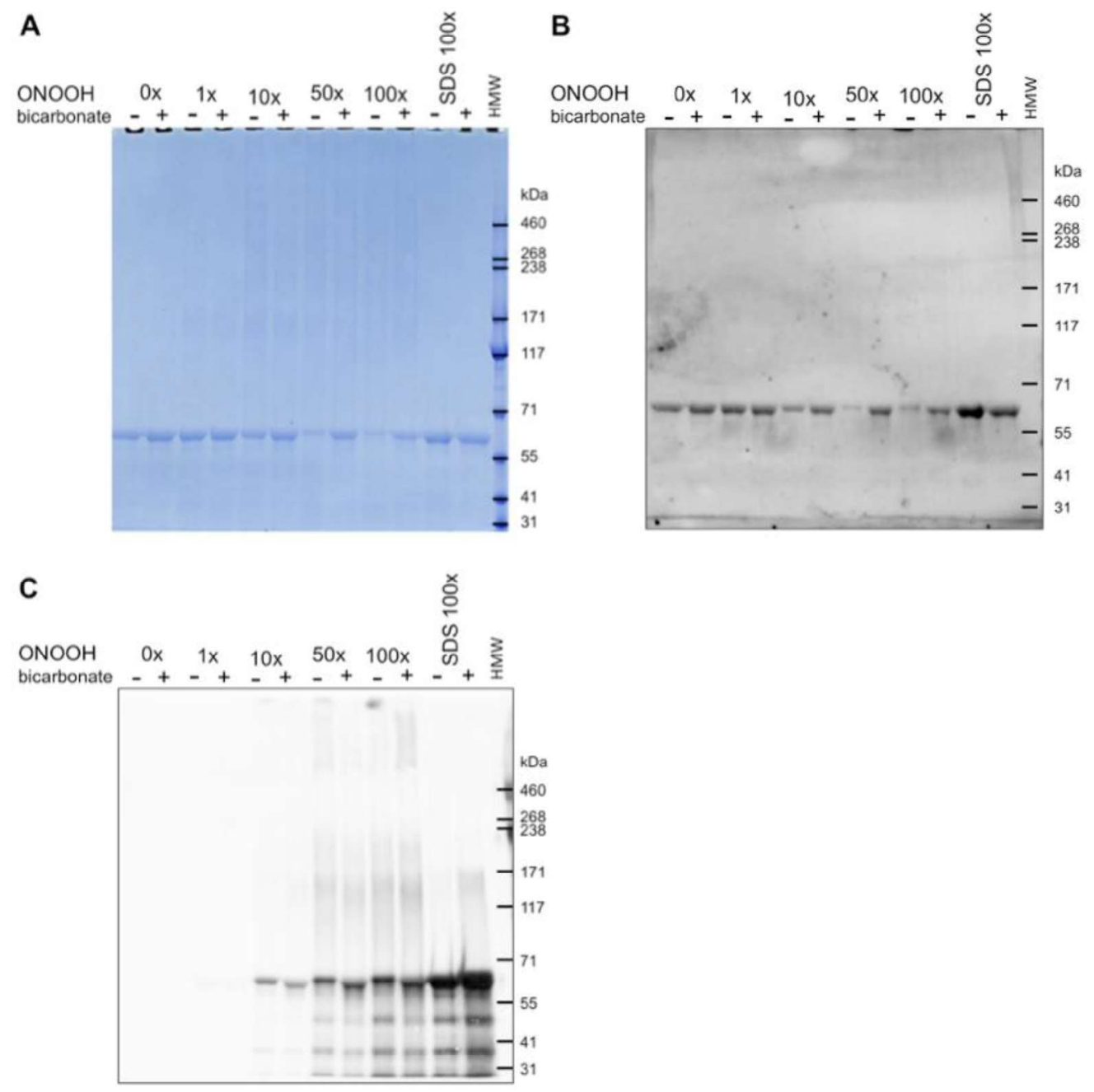


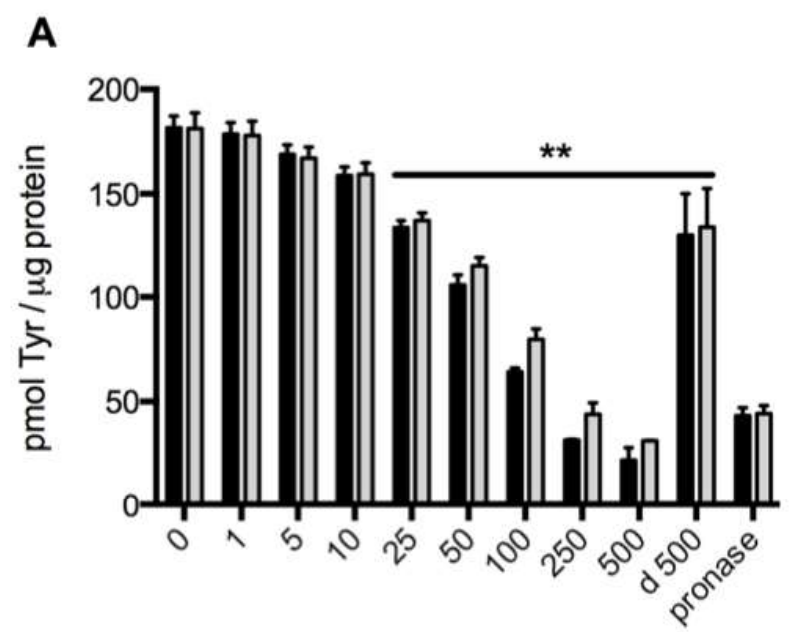

molar ratio $\mathrm{ONOOH}$ to elastin

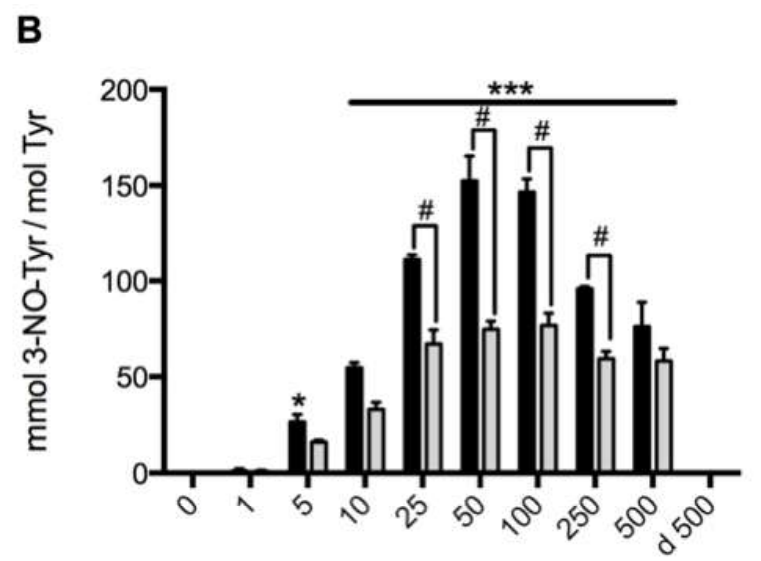

molar ratio $\mathrm{ONOOH}$ to elastin 


\section{ACCEPTED MANUSCRIPT}
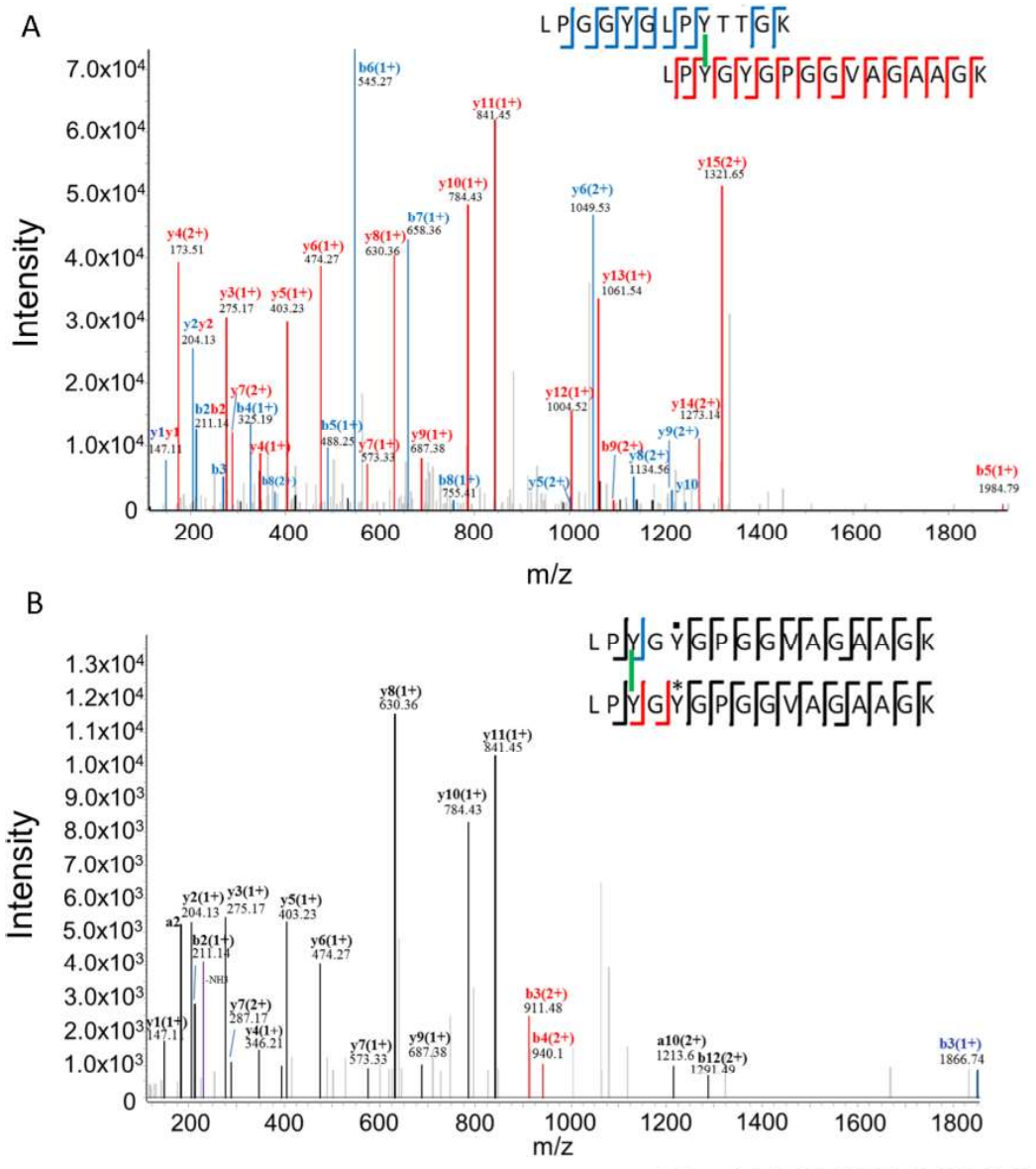

C

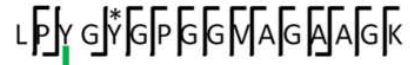

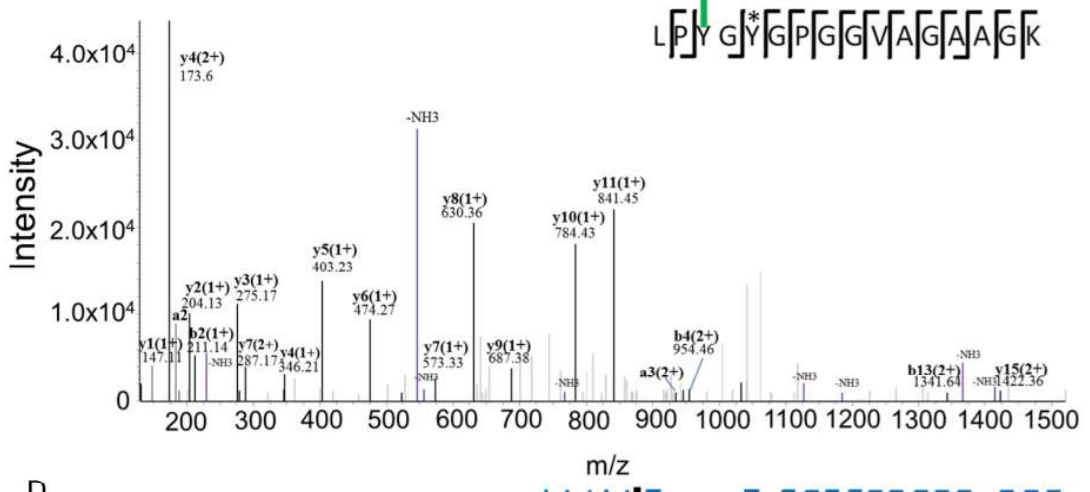

D

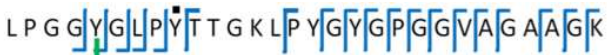

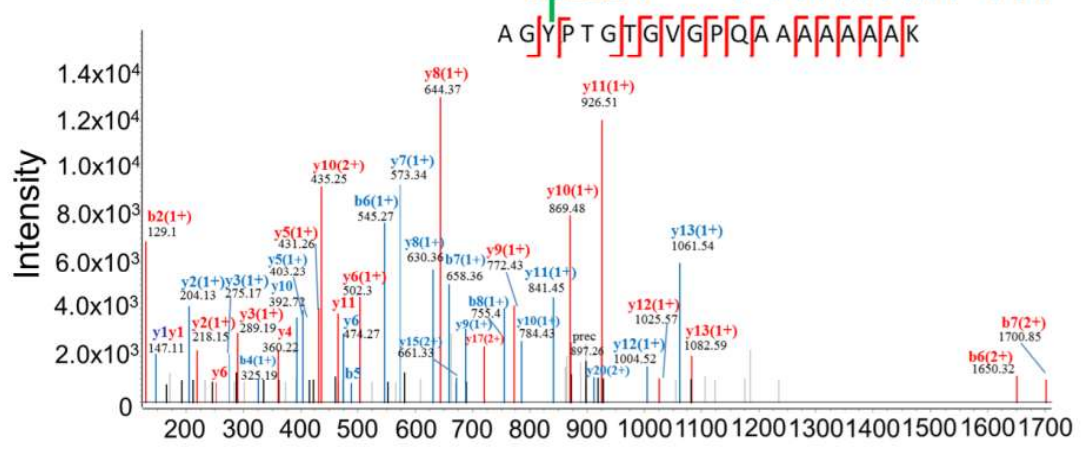

$\mathrm{m} / \mathrm{z}$ 


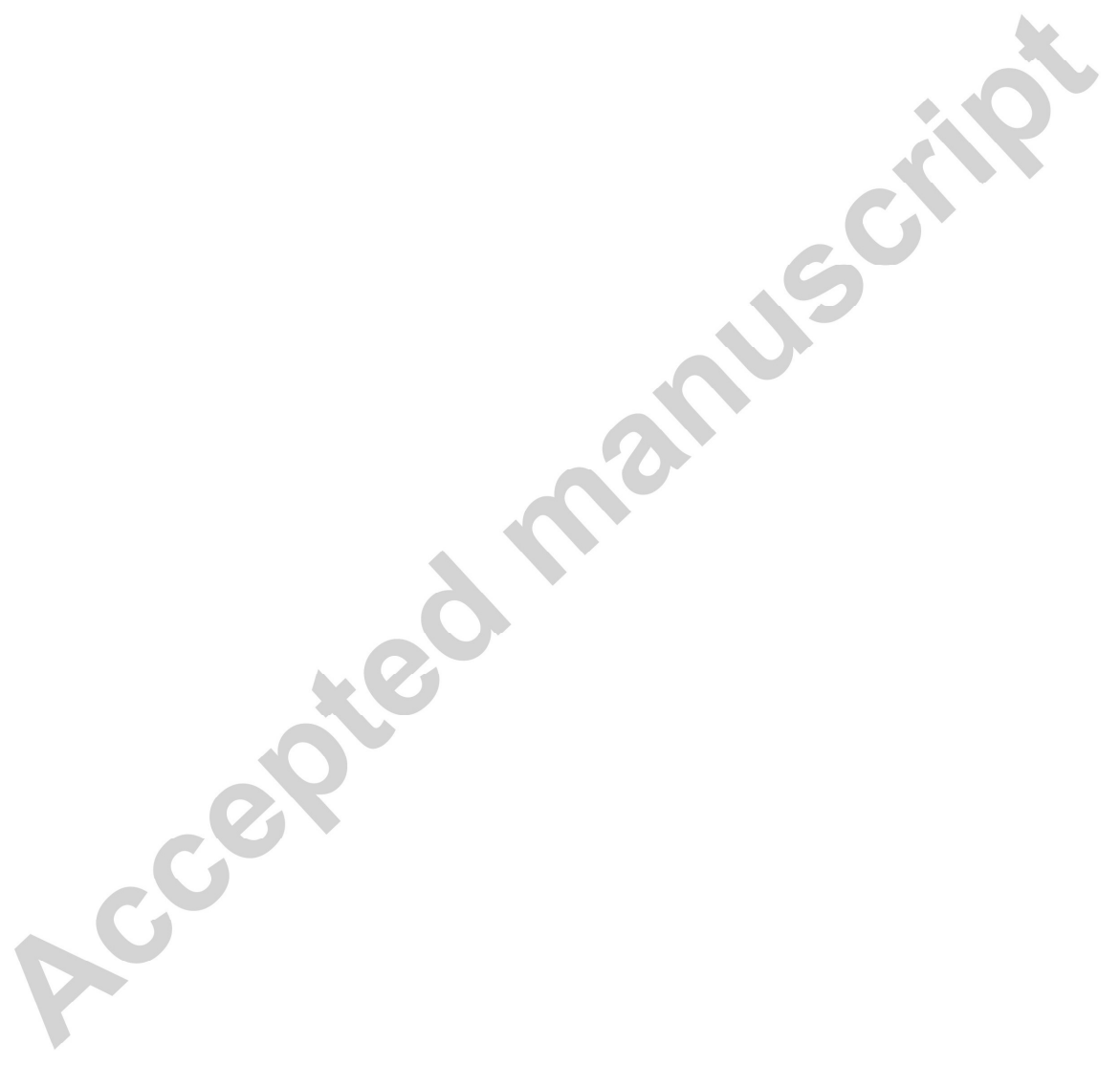




\section{ACCEPTED MANUSCRIPT}

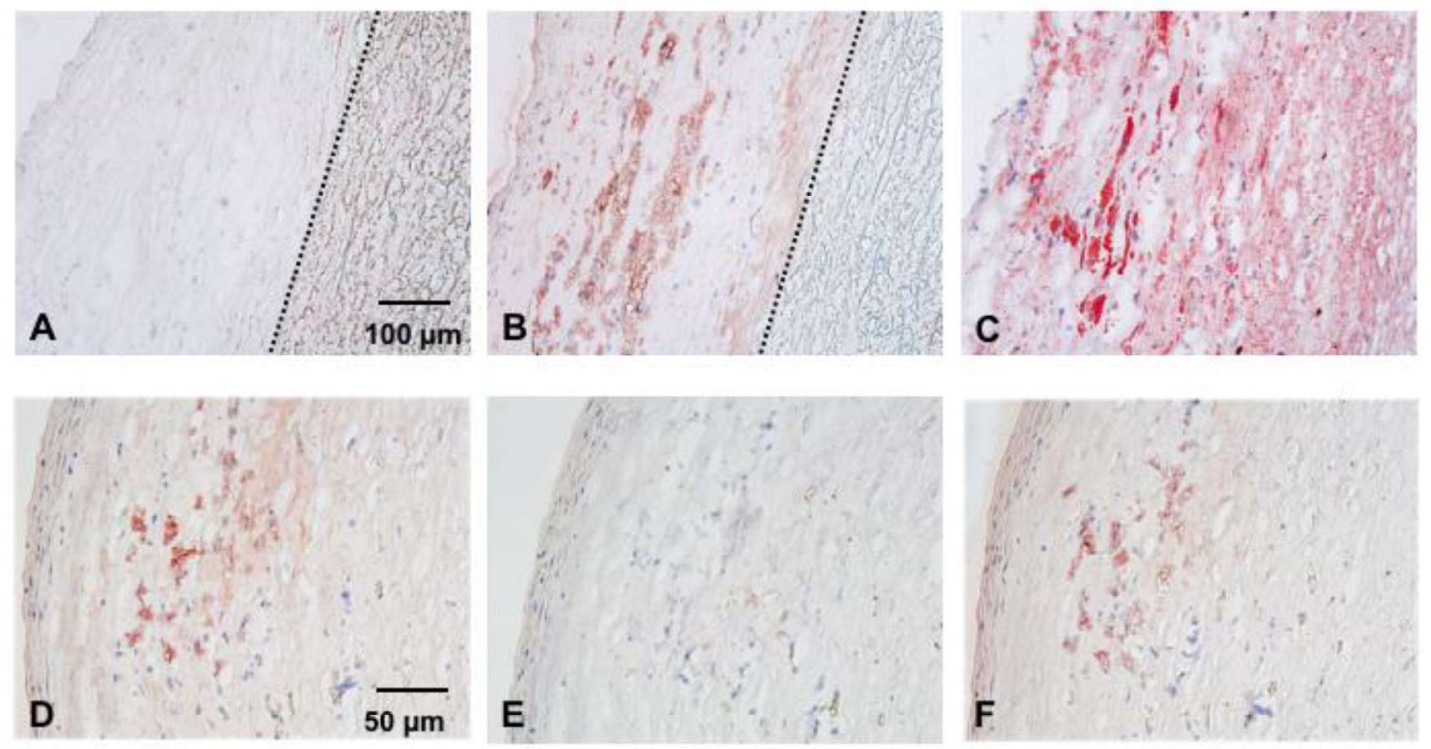




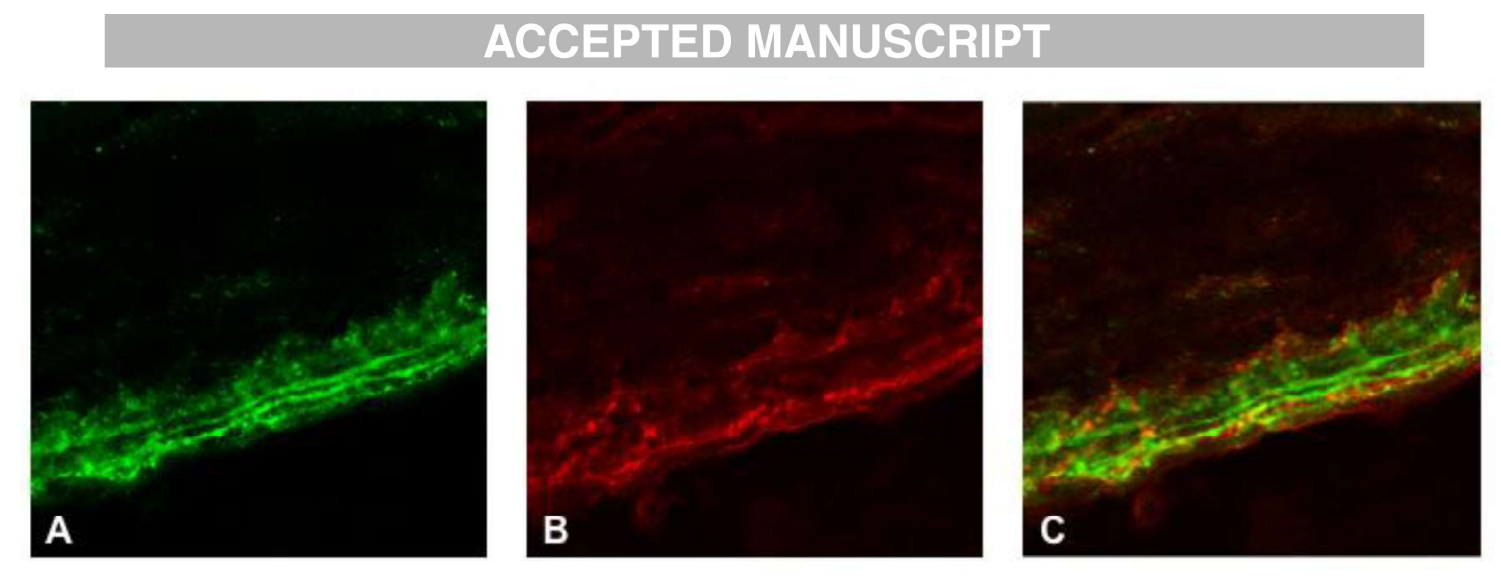




\section{ACCEPTED MANUSCRIPT}

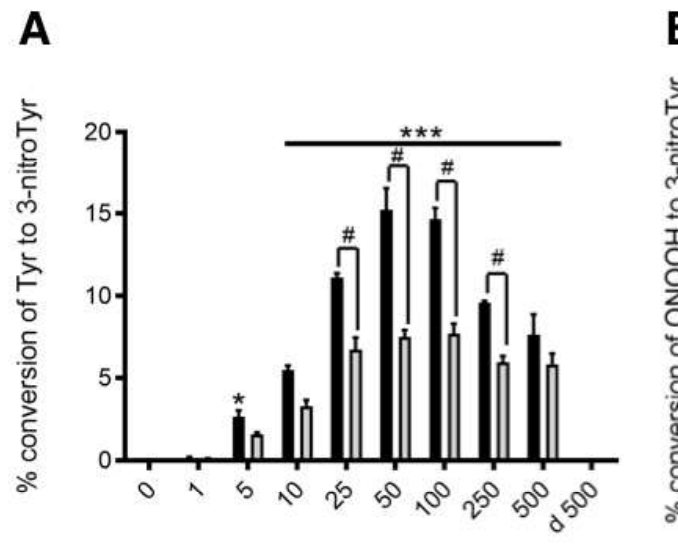

molar ratio $\mathrm{ONOOH}$ to elastin
B

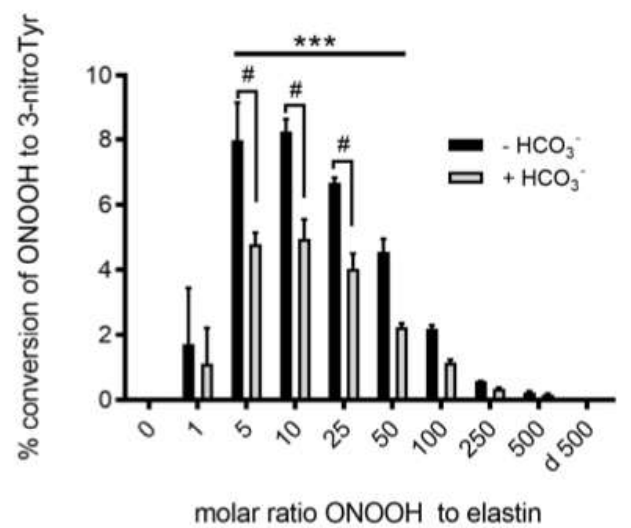




\begin{tabular}{|c|c|c|c|c|}
\hline \multirow{3}{*}{10} & \multicolumn{4}{|c|}{ ACCEPTED MANUSCRIPT } \\
\hline & 20 & 30 & 40 & 50 \\
\hline & & GGVP & GAIPGGVPGG & VFYPGAGLGA \\
\hline 60 & 70 & 80 & 90 & 100 \\
\hline LGGGALGPGG & KPLKPVPGGL & AGAGLGAGLG & AFPAVTFPGA & LVPGGVADAA \\
\hline 110 & 120 & 130 & 140 & 150 \\
\hline AAYKAAKAGA & GLGGVPGVGG & LGVSAGAVVP & QPGAGVKPGK & VPGVGLPGVY \\
\hline 160 & 170 & 180 & 190 & 200 \\
\hline PGGVLPGARF & PGVGVLPGVP & TGAGVKPKAP & GVGGAFAGIP & GVGPFGGPQP \\
\hline 210 & 220 & 230 & 240 & 250 \\
\hline GVPLGYPIKA & PKLPGGYGLP & YTTGKLPYGY & GPGGVAGAAG & KAGYPTGTGV \\
\hline 260 & 270 & 280 & 290 & 300 \\
\hline GPQAAAAAAA & KAAAKFGAGA & AGVLPGVGGA & GVPGVPGAIP & GIGGIAGVGT \\
\hline 310 & - 320 & 330 & 340 & 350 \\
\hline PAAAAAAAAA & AKAAKYGAAA & GLVPGGPGFG & PGVVGVPGAG & VPGVGVPGAG \\
\hline 360 & 370 & 380 & 390 & 400 \\
\hline IPVVPGAGIP & GAAVPGVVSP & EAAAKAAAKA & AKYGARPGVG & VGGIPTYGVG \\
\hline 410 & 420 & 430 & 440 & 450 \\
\hline AGGF PGFGVG & VGGIPGVAGV & PGVGGVPGVG & GVPGVGISPE & AQAAAAAKAA \\
\hline 460 & 470 & 480 & 490 & 500 \\
\hline KYGAAGAGVL & GGLVPGPQAA & VPGVPGTGGV & PGVGTPAAAA & AKAAAKAAQF \\
\hline 510 & 520 & 530 & 540 & 550 \\
\hline GLVPGVGVAP & GVGVAPGVGV & APGVGLAPGV & GVAPGVGVAP & GVGVAPGIGP \\
\hline 560 & 570 & 580 & 590 & 600 \\
\hline GGVAAAAKSA & AKVAAKAQLR & AAAGLGAGIP & GLGVGVGVPG & LGVGAGVPGL \\
\hline 610 & 620 & 630 & 640 & 650 \\
\hline GVGAGVPGFG & AGADEGVRRS & LSPELREGDP & SSSQHLPSTP & SSPRVPGALA \\
\hline 660 & 670 & 680 & 690 & 700 \\
\hline AAKAAKYGAA & VPGVLGGLGA & LGGVGIPGGV & VGAGPAAAAA & AAKAAAKAAQ \\
\hline 710 & 720 & 730 & 740 & 750 \\
\hline FGLVGAAGLG & GLGVGGLGVP & GVGGLGGIPP & AAAAKAAKYG & AAGLGGVLGG \\
\hline 760 & 770 & 780 & & \\
\hline AGQF PLGGVA & ARPGFGLSPI & FPGGACLGKA & CGRKRK & \\
\hline
\end{tabular}

